\title{
APLICAÇÃO DA AURICULOTERAPIA VERDADEIRA E SHAM NO TRATAMENTO DE ESTRESSE EM ENFERMEIROS
}

\begin{abstract}
Dissertação apresentada ao Programa de Pós-Graduação em Enfermagem na Saúde do Adulto da Escola de Enfermagem da Universidade de São Paulo para obtenção do título de Mestra em Ciências
\end{abstract}

Área de concentração: Enfermagem na Saúde do Adulto

Orientadora: Prof ${ }^{\mathrm{a}}{ }^{-\mathrm{a}}{ }^{\mathrm{a}}$ Maria Julia Paes da Silva

\section{SÃO PAULO}


AUTORIZO A REPRODUÇÃO E DIVULGAÇÃO TOTAL OU PARCIAL DESTE TRABALHO, POR QUALQUER MEIO CONVENCIONAL OU ELETRÔNICO, PARA FINS DE ESTUDO E PESQUISA, DESDE QUE CITADA A FONTE.

Assinatura:

Data:

\section{Catalogação na Publicação (CIP)}

Biblioteca "Wanda de Aguiar Horta"

Escola de Enfermagem da Universidade de São Paulo

Prado, Juliana Miyuki do

Aplicação da auriculoterapia verdadeira e sham no tratamento de estresse em enfermeiros. -- São Paulo, 2014.

$98 \mathrm{p}$.

Dissertação (Mestrado) - Escola de Enfermagem da Universidade de São Paulo.

Orientadora: Profa. Dra. Maria Júlia Paes da Silva

Área de concentração: Enfermagem na Saúde do Adulto

1. Terapias complementares. 2. Acupuntura. 3. Estresse - redução.

4. Estresse profissional. 5. Enfermagem. I. Título. 
Nome: Juliana Miyuki do Prado

Título: Aplicação da Auriculoterapia Verdadeira e Sham para tratamento de estresse em enfermeiros.

Dissertação apresentada ao Programa de Pós-Graduação em Enfermagem na Saúde do Adulto da Escola de Enfermagem da Universidade de São Paulo para obtenção do título de Mestra em Ciências.

Aprovado em:

\section{Banca Examinadora}

Prof. Dr. Instituição:

Julgamento: Assinatura:

Prof. Dr. Instituição:

Julgamento: Assinatura:

Prof. Dr. Instituição:

Julgamento: Assinatura: 


\section{DEDICATÓRIA}

À minha mãe, por estar sempre presente em minha vida, pelo incentivo, por ser o exemplo de força e dedicação. Minha gratidão eterna por continuar cuidando de nossa família com tanto zelo e amor.

Às minhas sobrinhas, Clarinha e Gabi, que desde o início me ensinaram o amor incondicional e o quanto é maravilhoso ser tia e madrinha. À minha irmã Camila e ao meu cunhado Fernando pelo carinho e pela confiança depositada. 


\section{AGRADECIMENTOS ESPECIAIS}

À minha querida orientadora Prof ${ }^{a}$ Dr ${ }^{a}$ Maria Julia Paes da Silva pela oportunidade de crescimento profissional e pessoal e de aprendizado como pesquisadora. Obrigada pela paciência e incentivo. Obrigada por despertar ainda mais meu interesse em práticas integrativas desde a graduação.

À minha professora de acupuntura $\operatorname{Dr}^{\mathrm{a}}$ Leonice Fumiko Sato Kurebayashi pelos ensinamentos sobre acupuntura e demais práticas integrativas. Muito obrigada por despertar em mim o interesse em outras formas de cuidar. Obrigada pela orientação, acolhimento, ajuda e força. Serei eternamente grata por tudo.

À querida professora $\operatorname{Dr}^{\mathrm{a}}$ Ana Lucia Siqueira Costa e à querida $\mathrm{Dr}^{\mathrm{a}}$ Léia Fortes Salles pela participação no Exame de Qualificação e pelas valiosas contribuições que possibilitaram a realização desse estudo.

Ao Ricky, companheiro de vida, por todos esses anos de convivência e amizade. Por me ajudar não apenas durante todo o período desse estudo, mas durante todos esses anos de parceria. Por estar presente sempre quando eu precisei. Obrigada pela paciência, pelo carinho, pelo respeito e por todos os momentos que passamos juntos. 


\section{AGRADECIMENTOS}

A todos meus amigos, pela torcida, carinho e presença em todos os momentos da minha vida. Obrigada por caminharem ao meu lado ao longo de todos esses anos.

Aos queridos amigos: Ray, Katia e Yuka pela amizade, incentivo, força durante toda essa trajetória. E por tornarem os momentos mais leves e divertidos com suas presenças.

Às amigas da faculdade, "gatas garotas", obrigada pela torcida e por continuar somando boas histórias de convivência desde o primeiro ano de graduação.

Às colegas da Escola de Enfermagem São Joaquim pelo apoio e convivência. Em especial à diretora Cleide Maria Ferreira da Silva Zorze, pela compreensão e por possibilitar meu desenvolvimento como docente em Enfermagem. À amiga Gilmara pelas conversas e cafezinhos extremamente necessários para aguentar a jornada triplicada durante todo esse período.

À enfermeira Denise Alves Saltini por autorizar e possibilitar a realização da pesquisa com os enfermeiros do Hospital Beneficência Portuguesa de São Paulo.

Às colegas da Educação Continuada do Hospital Beneficência Portuguesa de São Paulo (Unidade São Joaquim), pelo acolhimento, incentivo, carinho e parceria nessa nova jornada de trabalho e força nessa etapa final.

A todos os enfermeiros do Hospital Beneficência Portuguesa de São Paulo (Unidade São Joaquim) que participaram e viabilizaram a realização do estudo. Muito obrigada pela contribuição e paciência! 


\section{EPÍGRAFE}

Todo conhecimento começa com o sonho. O conhecimento nada mais é que a aventura pelo mar desconhecido, em busca da terra sonhada. Mas sonhar é coisa que não se ensina. Brota das profundezas do corpo, como água brota das profundezas da terra. Como mestre só posso então Ihe dizer uma coisa: "Conte-me os seus sonhos, para que sonhemos juntos!"

(Rubem Alves, 2012) 
Prado JM. Aplicação da Auriculoterapia Verdadeira e Sham para tratamento de estresse em enfermeiros [dissertação]. São Paulo: Escola de Enfermagem, Universidade de São Paulo; 2014.

\section{RESUMO}

Introdução: O estresse ocupacional na área da Enfermagem está relacionado a fatores multidimensionais, como condições de trabalho, relacionamento interpessoal, gerenciamento do trabalho e vida pessoal, entre outros. $O$ estresse excessivo afeta 0 desempenho e produtividade no trabalho e provoca disfunções e doenças. A auriculoterapia tem se mostrado como uma das práticas integrativas eficazes para 0 tratamento do estresse, além de apresentar custo financeiro reduzido e não necessitar de tempo prolongado para sua realização; portanto, pode ser uma técnica indicada para realização dentro do ambiente dinâmico como o ambiente hospitalar. Objetivos: Comparar a eficácia terapêutica da auriculoterapia verdadeira e sham no tratamento de estresse identificado nos enfermeiros do Hospital Beneficência Portuguesa de São Paulo Método: Responderam a ficha de dados sóciodemográficos e foram avaliados quanto ao nível de estresse pela Lista de Sintomas de Stress (LSS) e pela Escala Visual Analógica 257 enfermeiros de diferentes turnos de trabalho e setores. 168 apresentaram níveis médio e alto de estresse e foram randomizados em três grupos: Controle, Placebo e Auriculoterapia. 133 finalizaram o estudo. Os grupos Placebo e Auriculoterapia receberam 12 sessões de auriculoterapia, 2 vezes por semana. Os pontos utilizados para o Grupo Placebo foram Ouvido Externo e Área da Bochecha. Para o Grupo Auriculoterapia foram escolhidos os pontos Shen Men e Tronco Cerebral. A LSS foi aplicada no início, após 8 sessões, após 12 sessões e no follow-up de 15 dias, inclusive para o Grupo Controle. A coleta foi realizada no período de outubro de 2013 a fevereiro de 2014, após aprovação pelos Comitês de Ética em Pesquisa da EEUSP e do Hospital. Resultados: O nível de estresse prevalente em todos os turnos de trabalho foi o nível alto, com 
$43,58 \%$ dos participantes. Os enfermeiros com cargos administrativos apresentaram média de 59,43 de nível de estresse, enquanto os assistenciais 54,59. Quanto à evolução dos níveis de estresse, não houve diferença entre os momentos de avaliação no Grupo Controle. O Grupo Auriculoterapia apresentou diferença entre a primeira avaliação e as demais $(p<0,001)$, ou seja, a redução dos níveis de estresse ocorreu a partir da segunda avaliação com 8 sessões. Já o Grupo Placebo apresentou diferença apenas entre a primeira e terceira avaliação após 12 sessões $(p<0,001)$. Conclusão: Os pontos Shen Men e Tronco Cerebral foram eficazes para redução do estresse em enfermeiros com 8 sessões de auriculoterapia, 12 sessões e com follow up de 15 dias $(p<0,001$ em todos os momentos). Além disso, os pontos selecionados como pontos sham, Ouvido Externo e Área da Bochecha/Face, podem ser utilizados como pontos placebos em estudos de estresse.

PALAVRAS-CHAVE: Acupuntura. Terapias complementares. Estresse profissional. Enfermagem. 
Prado JM. Application of true and sham auriculotherapy for nurse's stress treatment. [dissertation]. São Paulo: School of Nursing, São Paulo University; 2014.

\section{ABSTRACT}

Introduction: Occupational stress in Nursing is related to multidimensional factors, like work conditions, interpersonal relationship, work management and personal life. Excessive stress affects work productivity and performance and provokes dysfunctions and diseases. Auriculotherapy has been shown like one of effective integrative practices for stress treatment, beyond to present reduced financial cost and not to need a long time to be applicated. Therefore it can be a suggested practice to be achieved in a dynamic environment like a hospital. Obectives: To compare the therapeutic efficacy of true and sham auriculotherapy in the treatment of identified stress in nurses of Beneficência Portuguesa Hospital of São Paulo. Method: 257 nurses of different shifts and departments answered the social data demographic form and were evaluated in the stress level by List of Stress Symptoms (LSS) and Analogic Visual Scale. 168 nurses reported high and middle stress levels and were randomized in 3 groups: Control, Placebo and Auriculotherapy. 133 ended the study. The groups Placebo and Auriculotherapy received 12 sessions of auriculotherapy, twice a week. The points used for Placebo group were External Ear and Cheek area. For Auriculotherapy group were chosen the points Shen Men and Brainstem. LSS was applied in the beginning, after 8 sessions, after 12 sessions and in 15 day follow up, including for Control group. The data collection was done from October 2013 to February 2014, after approval by the Ethic Committees in Research of EEUSP and of Beneficência Portuguesa Hospital. Results: The level of stress prevalent in all the work shifts was high level with $43,58 \%$ of the participants. The nurses with administrative positions presented average of 59,43 of stress level, while assistencial position 54,59 . About the evolution of stress level, there wasn't any difference 
among the moments of evaluation in the Control group. Auriculotherapy group performed difference among the first evaluation and the following ones $(p<0,001)$, that is the reduction of the stress levels occurred from the second evaluation with 8 sessions. The Placebo group showed a difference only between the first and third evaluation after 12 sessions. Conclusion: The points were effective to reduce the stress in nurses with 8 sessions of auriculotherapy, 12 sessions and with 15-day follow up ( $p<0,001$ in all the moments). Besides, the selected points like sham, External Ear and Cheek area, can be used like placebo points in stress studies.

KEYWORDS: Acupuncture. Complementary therapies. Professional stress. Nursing. 


\section{LISTA DE FIGURAS}

Figura 1 - llustração esquemática das respostas

fisiológicas do estresse. São Paulo, 2014........

Figura 2 - llustração do pavilhão auricular e imagem fetal. São Paulo, 2014............................................

Figura 3 - Áreas no pavilhão auricular segundo origem embriológica. São Paulo, 2014.........................

Figura 4 - Principais inervações do pavilhão auricular. São Paulo, 2014............................................. 36

Figura 5 - Fluxograma de participação dos enfermeiros. São Paulo, 2014......................................... 44

Figura 6 - Áreas inervadas e pontos da pesquisa. São Paulo, 2014. 


\section{LISTA DE GRÁFICOS}

Gráfico 1 - Distribuição dos participantes segundo sexo. São Paulo, 2014

Gráfico 2 - Distribuição dos participantes segundo estado civil. São Paulo, 2014........................................................

Gráfico 3 - Distribuição dos participantes segundo pósgraduação. São Paulo, 2014

Gráfico 4 - Evolução do escore de estresse entre os grupos ao longo das avaliações. São Paulo, 2014............... 


\section{LISTA DE TABELAS}

Tabela 1 - Média e Desvio Padrão das variáveis: Idade, Tempo de formado (anos), Tempo de trabalho no setor

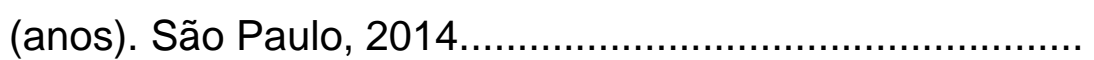

Tabela 2 - Média e Desvio Padrão da pontuação de LSS dos tipos de cargos. São Paulo, 2014

Tabela 3 - Frequência e percentual dos participantes segundo níveis de estresse. São Paulo, 2014

Tabela 4 - Frequência e percentual de participantes segundo níveis de estresse pela Escala Visual Analógica (EVA). São Paulo, 2014.

Tabela 5 - Distribuição dos participantes nos turnos de trabalho segundo os níveis de estresse. São Paulo, 2014..

Tabela 6 - Frequência dos participantes, média e desvio padrão da pontuação de estresse segundo tipos de setores. São Paulo, 2014

Tabela 7 - Distribuição dos participantes que trabalham ou não em outra instituição, segundo carga horária semanal. São Paulo, 2014

Tabela 8 - Média e desvio padrão dos escores da LSS dos grupos experimentais em cada avaliação. São Paulo, 2014 


\section{SUMÁRIO}

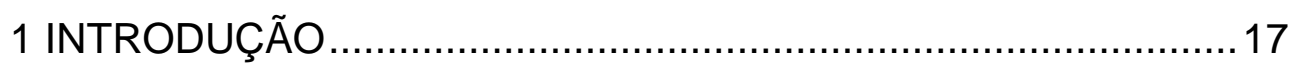

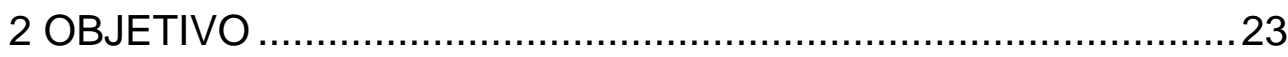

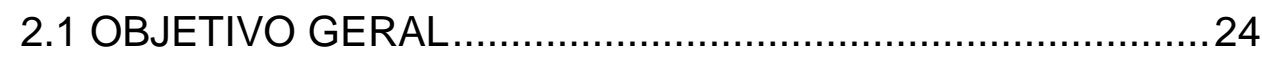

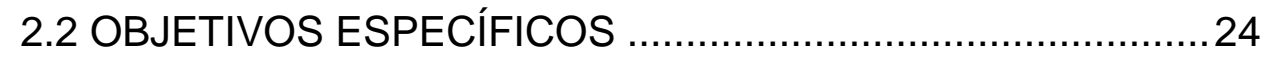

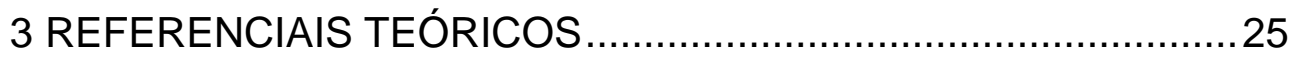

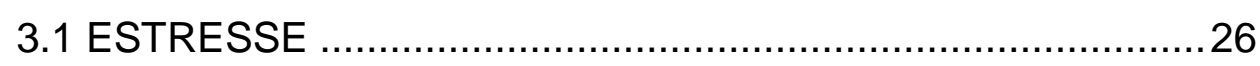

3.1.2 Estresse Ocupacional..................................................... 30

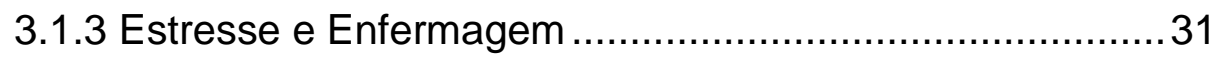

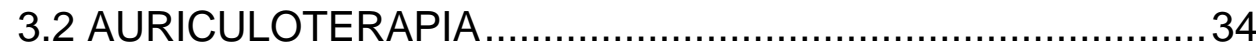

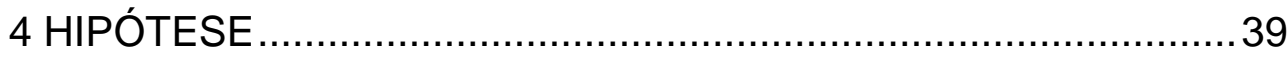

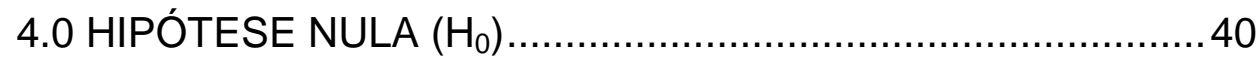

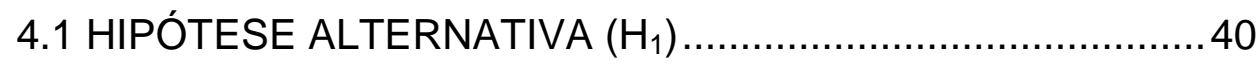

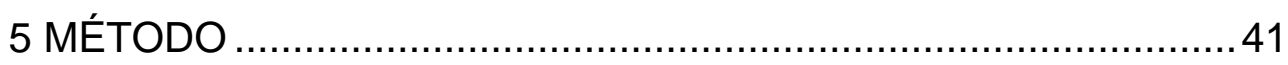

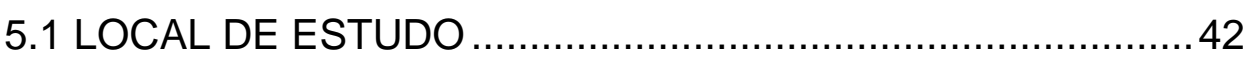

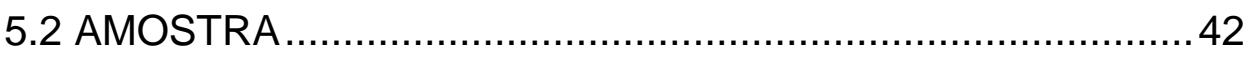

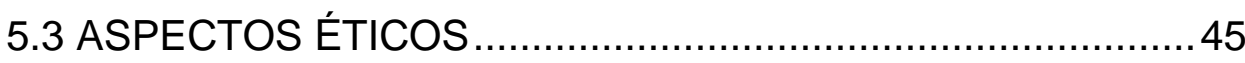

5.4 INSTRUMENTOS DE COLETA DE DADOS ……...................45

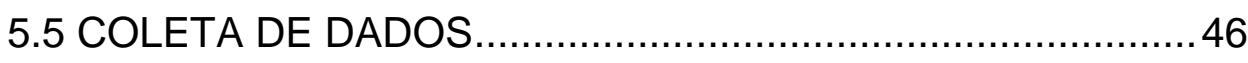

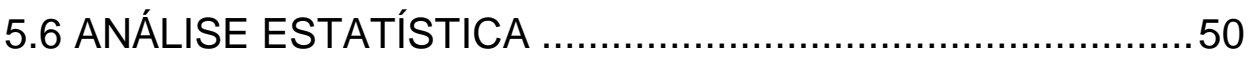

6 RESULTADOS

6.1 DESCRITIVA DOS DADOS SÓCIO-DEMOGRÁFICOS..........52

6.2 ANÁLISE INTERGRUPOS E EVOLUÇÃO DOS NÍVEIS DE ESTRESSE SEGUNDO A LSS E EVA ......................59

6.3 TESTE DE CORRELAÇÃO ENTRE LSS E EVA....................61

6.4 REGRESSÃO LINEAR ENTRE OS NÍVEIS DE ESTRESSE E CARGO, SETOR E TURNO DE

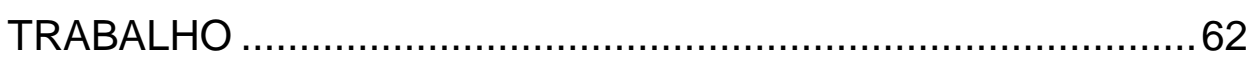

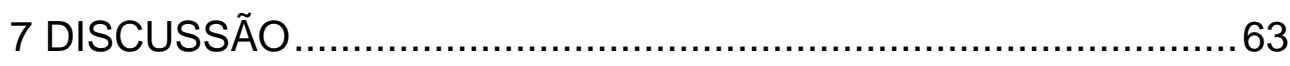

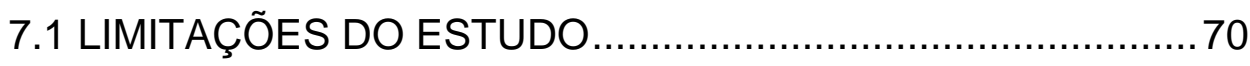

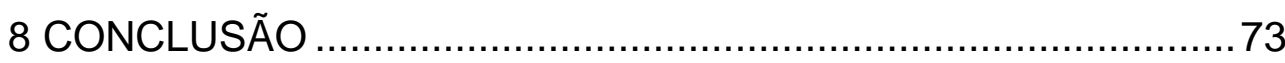

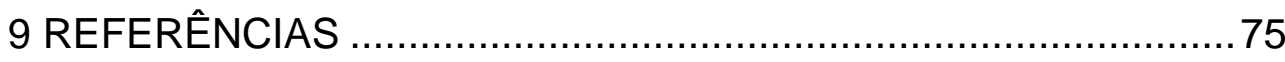




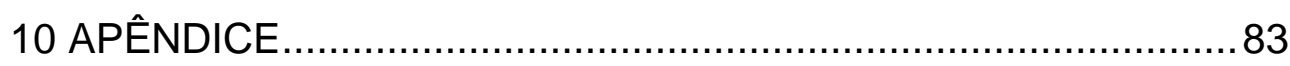

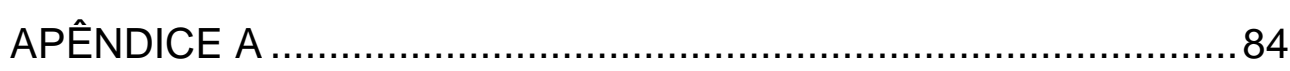

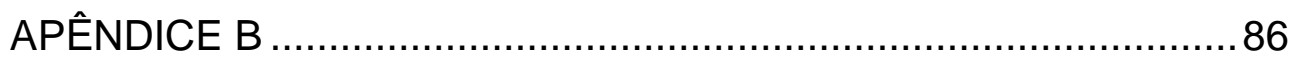

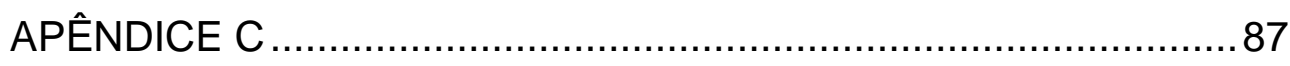

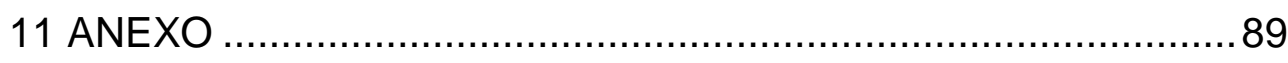

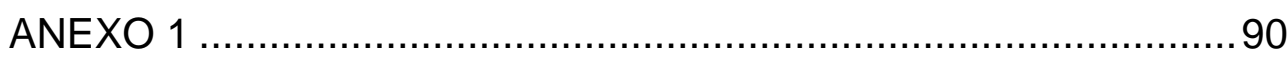

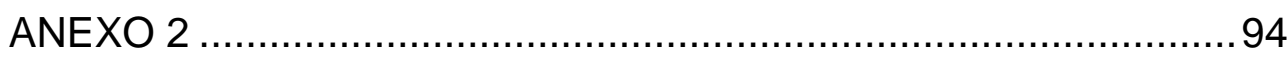

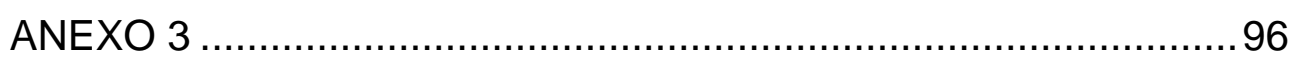


Estresse é um tema muito discutido na atualidade, popularmente e cientificamente, por meio de estudos realizados por diferentes profissionais. Está presente no âmbito pessoal e profissional. Há um consenso de que a Enfermagem é uma profissão estressante. $O$ enfermeiro é um profissional que presta assistência ao paciente e família, convivendo com situações conflitantes, como sofrimento e morte, nascimento e recuperação, principalmente dentro do ambiente hospitalar (Bianchi, 2009).

$O$ estresse influencia no bem-estar biopsicossocial do indivíduo e, além de ter consequências negativas no desempenho profissional, pode afetar a instituição e o processo de trabalho, por meio do absenteísmo, alta rotatividade de profissionais e baixa qualidade da assistência (Guido et al., 2011).

O controle de fatores estressores depende da forma como cada um aprende a lidar com os desafios e dificuldades que o cercam, pois o estresse é uma reação biológica natural de enfrentamento de situações. Só se torna patológico quando há um rompimento do equilíbrio do organismo, fazendo com que alguns órgãos trabalhem mais e outros menos para poder lidar com 0 problema (Lipp, 1996).

O conjunto de estratégias utilizadas pelo indivíduo para se adaptar a situações adversas é denominado coping. Os principais estudiosos desse tema foram Folkman e Lazarus, que em uma perspectiva cognitivista, propõem um modelo dividido em coping focalizado no problema e coping focalizado na emoção. Portanto, nessa perspectiva, coping é definido como um conjunto de esforços, cognitivos e comportamentais, que os indivíduos utilizam para lidar com demandas internas ou externas originadas de situações de estresse e avaliadas como prejudiciais (Antoniazzi, Dell'Aglio, Bandeira, 1998).

Apesar do interesse pelo estudo sobre estresse relacionado à profissão de Enfermagem ter começado a partir da década de 90 no Brasil, pouco se discute sobre estratégias para minimizar o estresse 
ocupacional entre enfermeiros. Acredita-se que as práticas complementares em saúde podem ser utilizadas como estratégias de enfrentamento de situações de estresse. Essas práticas têm se mostrado eficazes no controle e tratamento de doenças, além de proporcionar melhor qualidade de vida (Giaponesi, Leão, 2009; Kurebayashi et al, 2012; Nakai, 2007; Prado, Kurebayashi, Silva, 2012; Rocha, Silva, 2011).

Segundo a Lei Municipal de São Paulo no 13.717 de 2004, as práticas integrativas e complementares são definidas como práticas que utilizem recursos naturais para promoção de saúde e prevenção de doenças (São Paulo, 2004). Entre essas práticas, encontram-se a acupuntura, fitoterapia, homeopatia, entre outras.

A auriculoterapia, ou acupuntura auricular, faz parte de um conjunto de técnicas terapêuticas, baseada nos preceitos da Medicina Tradicional Chinesa (MTC). Acredita-se que tenha sido desenvolvida juntamente com a acupuntura sistêmica que, atualmente, é uma das práticas orientais mais populares em diversos países e tem sido amplamente utilizada na assistência à saúde, nos aspectos preventivos e curativos (Souza, 2001). A auriculoterapia é uma prática que apresenta importantes vantagens por sua simplicidade na aplicação. Primeiro, exige pouco equipamento e não necessita de grande espaço físico para sua realização. É uma técnica rápida, o tempo gasto para sua aplicação não se estende mais do que 10 a 15 minutos, com custo mínimo. Pode ser vantajosa, portanto, se comprovada sua eficácia como estratégia de enfrentamento do estresse ocupacional em enfermeiros hospitalares.

A partir da Portaria 971, as práticas integrativas e complementares foram aprovadas no Sistema Único de Saúde (SUS), dentre as quais se destaca a acupuntura, realizável por todos os profissionais de saúde como especialistas (Brasil, 2006). O Conselho Federal de Enfermagem (COFEN) reconheceu as terapias alternativas, entre elas a acupuntura, como especialidade e/ou 
qualificação do profissional enfermeiro pela Resolução COFEN no197/97 (Conselho Federal de Enfermagem, 1997), fixando a especialidade de Enfermagem pela Resolução COFEN no290/2004 (Conselho Federal de Enfermagem, 2004).

Para comprovação da eficácia de uma determinada técnica é recomendada a utilização de um grupo placebo-controle. $\mathrm{Na}$ acupuntura e auriculoterapia tem se estudado formas de placebo que não apresente tantos vieses (Lundeberg et al., 2009).

Em 2010 foi realizado um ensaio clínico randomizado com estudantes de nível médio de uma escola técnica de massoterapia e acupuntura, cuja proposta foi observar se a auriculoterapia verdadeira com os pontos Shen Men e Tronco Cerebral e a auriculoterapia sham com os pontos Punho e Ouvido Externo, apresentavam efeitos similares sobre os níveis de ansiedade $\mathrm{e}$ estresse. Os resultados obtidos não indicaram eficácia dos pontos de auriculoterapia verdadeira, com melhores resultados para os pontos sham (Rocha, Silva, 2011). Como os estudantes recebiam outros estímulos energéticos durante o curso, como massagem, reflexologia, acupuntura sistêmica, entre outros, foi realizado outro estudo, com o mesmo delineamento, em 2011, porém com estudantes de nível médio de Enfermagem que não apresentavam essa variável.

Neste novo ensaio clínico concluiu-se que a auriculoterapia verdadeira diminuiu os níveis de estresse e ansiedade em estudantes de Enfermagem. A auriculoterapia sham também apresentou melhora nos níveis de estresse e ansiedade, menor em termos percentuais, porém não estatisticamente significativa em comparação com a auriculoterapia verdadeira. Como limitações deste estudo, foram considerados a amostragem pequena e a escolha inadequada dos pontos sham, pois foram encontradas referências que o ponto "Punho" pode ser utilizado para o tratamento de distúrbio do sono, ansiedade, abstinência, déficit de concentração 
e euforia, justificando assim os resultados positivos obtidos neste estudo (Prado, Kurebayashi, Silva, 2012).

Os estudos anteriores sobre a eficácia da técnica não têm se mostrado conclusivos devido ao número inadequado de sujeitos e dificuldade no estabelecimento de protocolo para ser utilizado como placebo, portanto, é necessária a replicação em populações diversas com maior número de sujeitos.

Diante dessas reflexões, o presente estudo tem como proposta comparar a eficácia da técnica de auriculoterapia verdadeira e sham em situações de estresse em enfermeiros. Algumas indagações são levantadas, como: Quais pontos podem ser utilizados como pontos sham no tratamento do estresse? Quais os efeitos da auriculoterapia verdadeira e auriculoterapia com pontos sham para redução de estresse em enfermeiros? A auriculoterapia pode ser utilizada como estratégia de enfrentamento em situações de estresse no trabalho? 


\subsection{OBJETIVO GERAL}

Comparar a eficácia terapêutica da auriculoterapia verdadeira e sham no tratamento de estresse identificado nos enfermeiros do Hospital Beneficência Portuguesa de São Paulo - Unidade São Joaquim.

\subsection{OBJETIVOS ESPECÍFICOS}

- Identificar os níveis de estresse dos enfermeiros em diferentes cargos (administrativo ou assistencial) e em diferentes setores hospitalares;

- Analisar a aplicabilidade dos pontos Shen Men e Tronco Cerebral para diminuição de estresse, e ponto Ouvido Externo e região da Face como pontos sham. 


\subsection{ESTRESSE}

A relação do estresse com eventos emocionais e doenças começou a ser explorada no século XIX. No início do século XX, Sir William Osler, médico inglês, relacionou os eventos estressantes com trabalho excessivo e a reação do organismo ao estresse com preocupação, a partir da observação de um grupo de médicos com angina pectoris que apresentavam uma rotina de trabalho e preocupações com o desempenho (Lipp, 2010).

Hans Selye, enquanto estudante de medicina na Universidade de Praga, já apresentava interesse no estudo do estresse a partir de observações de respostas não específicas semelhantes em pessoas que passavam por situações angustiantes. Em 1926, denominou esse conjunto de reações como "Síndrome geral de adaptação" ou "Síndrome do estresse biológico". Em 1936, já endocrinologista, Selye sugeriu o uso da palavra estresse para definir esta síndrome. Dessa forma, deu-se a primeira definição de estresse na área da saúde (Lipp, 2010).

Por meio das pesquisas realizadas por Selye, o estresse foi definido como um conjunto de reações fisiológicas que o organismo desenvolve frente a uma situação de esforço, desencadeado por estímulo ameaçador à homeostase. $\mathrm{O}$ termo homeostase, sugerido em 1939 por Cannon, está relacionado ao esforço dos processos fisiológicos para manter um estado de equilíbrio corporal interno. As alterações descobertas em suas pesquisas envolvem redução do timo, dilatação do córtex das suprarrenais e surgimento de úlceras gastrintestinais.

O estresse, de acordo com Selye, consiste em três fases sucessivas: Fase de alerta ou alarme, Fase de adaptação ou resistência e Fase de Exaustão (Costa, 2003).

A Fase de alerta ocorre quando a pessoa percebe o agente estressor e se prepara para lutar ou fugir. Sob estímulo do sistema nervoso simpático há alterações hormonais e adrenalina e 
noradrenalina são secretadas pela glândula suprarrenal. Se a reação de alarme for bem sucedida, ocorre a cessação dos estímulos e o retorno à homeostasia interna do organismo, quando o estressor tem uma curta duração. Os sintomas presentes são: cefaleia, aumento da pressão arterial, mãos e pés frios, taquicardia, hiperventilação, aumento da sudorese, alterações gastrintestinais, tensão muscular, zumbido nos ouvidos, pressão no peito, irritabilidade, pesadelos.

Já a Fase de resistência consiste em um período de adaptação ao estresse. A pessoa tenta resistir fazendo uso de reservas de energia adaptativa em busca do reequilíbrio após a quebra da homeostase. É caracterizada por uma série de alterações neuroendócrinas. Os sintomas mais frequentes são a sensação de desgaste físico generalizado sem causa aparente, dificuldades com a memória, sensações de medo e nervosismo, oscilação de apetite, queda de cabelo, isolamento social. Ocorrem alterações nas suprarrenais e a medula diminui a produção de adrenalina, porém o córtex das suprarrenais produz mais corticóides. Se o estressor se mantiver por mais tempo, a pessoa entrará na fase de exaustão, tornando o organismo vulnerável a doenças e disfunções (Costa, 1997; Lipp, 2000).

Após a definição biológica de estresse por Selye, o conceito de estresse foi se modificando ao longo da história. No conceito atual, o estresse é definido como uma ameaça real ou interpretada à integridade física e psicológica de uma pessoa, que resulta em respostas biológicas e comportamentais. Situações consideradas novas, imprevisíveis, ameaçadoras ao ego e/ou incontroláveis contribuem para as respostas fisiológicas do estresse. Estas são ativadas pelos sistema nervoso autônomo (SNA) e neuroendócrino para mobilizar energia necessária à adaptação das demandas da situação, conforme ilustrado na Figura 1 a seguir (Juster et. al., 2011).

Primeiramente, ameaças percebidas e interpretadas acionam o eixo simpático-adrenal-medular (SAM) para liberação de 
catecolaminas, como por exemplo, adrenalina e noradrenalina (Juster et. al., 2011). O sistema simpático, por meio de sua ação direta sobre os órgãos, faz com que a adrenalina secretada pela adrenal em maior quantidade, seja levada pela corrente sanguínea a todos os tecidos do corpo, intensificando o metabolismo corporal e aumentando a excitabilidade e atividade do organismo em diversas situações. Dentre os efeitos produzidos, encontram-se: aumento da sudorese, dilatação ou contração das pupilas, aumento da secreção gástrica, da frequência e força de contração cardíaca, bronco dilatação, redução ou aumento do peristaltismo, aumento da contração da vasculatura periférica (Costa, 1997).

Após alguns minutos, o eixo hipotálamo-pituitária-adrenal (HPA) é ativado para produção de glicocorticóides. O hipotálamo, uma vez estimulado, libera o fator liberador de corticotrofina (CRF). A liberação desse fator promove a secreção do hormônio adrenocorticotrófico (ACTH) pela pituitária anterior ou adenohipófise, levando à liberação do cortisol pelas adrenais. Os picos de catecolaminas e glicocorticóides alteram a homeostase, ativando funções fisiológicas que permitem a reação de luta ou fuga. A função do cérebro durante a resposta do estresse é detectar a ameaça e se adaptar (Juster et. al., 2011).

O cortisol, principal glicocorticoide, tem importante efeito na gliconeogênese pelo fígado, elevando a concentração de glicose sanguínea. Em situações de estresse, é secretado em nível elevado para ajudar nas reações orgânicas exigidas, mobilizando aminoácidos e líquidos das reservas celulares como fonte de energia para os tecidos do organismo (Costa, 1997).

Além das atividades da pituitária e hipotálamo, há três estruturas cerebrais importantes envolvidas na regulação da resposta de estresse: hipocampo, ligado à memória e cognição, além de atuar na retroalimentação (feedback) negativa da regulação do eixo HPA; a amígdala, responsável pelo medo e emoções; e o córtex pré-frontal, envolvido na cognição e estratégias de 
enfrentamento, exercendo controle sobre as estruturas subcorticais. Em conjunto com o SNA, adaptações do organismo durante a resposta de estresse, em curto prazo, são processos biológicos dinâmicos que asseguram sobrevivência (Juster et. al., 2011).

Figura 1 - llustração esquemática das respostas fisiológicas do estresse. São Paulo, 2014.

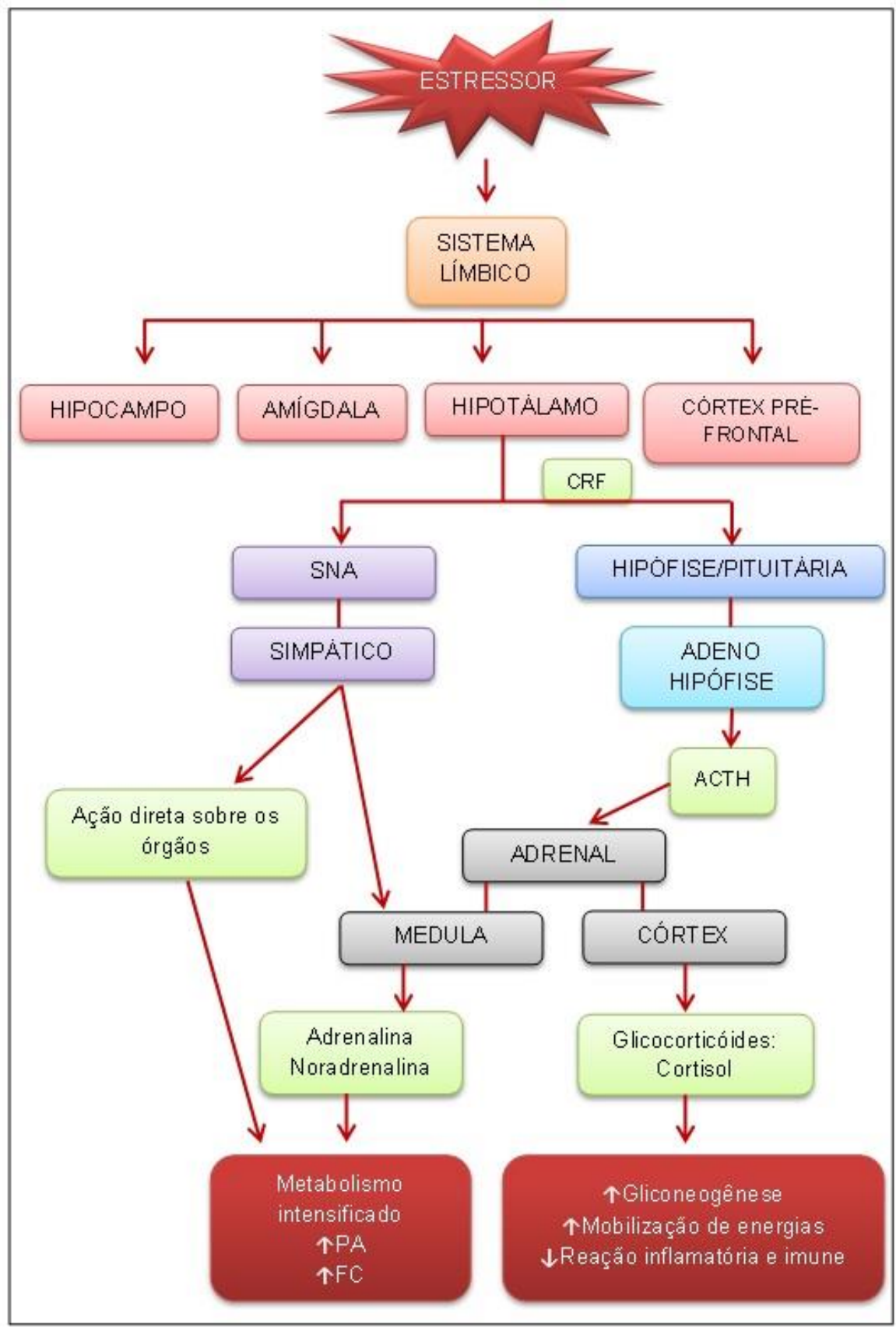

Fonte: Adaptado de Costa, ALS. Análise do stress nas situações de vida diária e do pré-operatório imediato de pacientes cirúrgicos urológicos. [Dissertação]. São Paulo(SP): Escola de Enfermagem, Universidade de São Paulo; 1997. 
O estresse excessivo provoca cansaço mental, dificuldade de concentração, perda de memória, apatia e indiferença emocional. Afeta a produtividade e a criatividade. A percepção do desempenho insatisfatório cria dúvidas sobre si, o que gera crises de ansiedade e humor depressivo. A qualidade de vida é afetada e frequentemente as pessoas com estresse excessivo sentem vontade de abandonar tudo (Lipp, 2010).

Quando o estresse se torna crônico, somam-se outros sintomas tais como aumento da glândula suprarrenal, que pode levar ao infarto, diminuição do timo e gânglios linfáticos, ocasionando depressão do sistema imune (Cardoso, 2001).

\subsubsection{Estresse Ocupacional}

Os maiores estressores são relacionados à família e ao trabalho, que se configuram como ambientes permanentes geradores de situações de estresse crônico. O estresse ocupacional é frequente quando há muitas responsabilidades, mas poucas possibilidades de tomada de decisão e de controle. Estressores ocupacionais estão frequentemente relacionados à organização do trabalho, como carga de trabalho excessiva, insalubridade, falta de treinamento e orientação, relacionamento interpessoal entre líderes e subordinados, falta de controle sobre a tarefa e ciclos trabalhodescanso incoerentes com os limites biológicos (Camelo, Angerami, 2008). Além de fatores como condições e natureza do trabalho, estrutura e clima organizacional e desenvolvimento da carreira profissional (Engel, 2004).

Além dos riscos físicos, químicos e biológicos existentes no ambiente ocupacional, há os riscos psicossociais, oriundos da relação do trabalho com seu ambiente, com as condições de sua organização, satisfação no trabalho, e também da interação entre as capacidades do profissional, suas necessidades, cultura e sua vida pessoal. Esses riscos podem influenciar na saúde e rendimento do 
profissional (Camelo, Angerami, 2008). Estressores de longa duração trazem consequências mais intensas aos profissionais.

Fatores de estresse no trabalho podem desencadear a Síndrome de Burnout, que é uma reação de estresse crônico, que causa no indivíduo indisposição, mal-estar em decorrência do trabalho. Acomete, principalmente, profissionais em contato direto com pessoas e expostos a sobrecarga de trabalho. É um fenômeno psicossocial que abrange três dimensões que justificam a insatisfação pessoal com o desempenho no trabalho: exaustão emocional (esgotamento), despersonalização (com relação aos clientes) e baixa realização profissional (auto-avaliação negativa) (Borges, Carlotto, 2004).

\subsubsection{Estresse e Enfermagem}

O estudo do estresse entre enfermeiros começou na década de 60, porém, no Brasil, somente na década de 90 que começaram as publicações na área, devido sua relevância no cenário da profissão (Bianchi, 2000; Elias, Navarro 2006; Ferreira, Martino, 2006; Murofuse, Abranches, Napoleão, 2005; Silva, Melo, 2006).

A prática de Enfermagem ocorre em diversas condições e está sujeita a constantes mudanças e experiências, que expõem o profissional a uma variedade de sentimentos e emoções. $\mathrm{Na}$ área da saúde, enfermeiros lidam com o sofrimento e a morte, conflitos, falta de preparo e de suporte em seu trabalho. Também com questões éticas e morais, rápidos avanços tecnológicos e questões legais. Essas mudanças na área da saúde têm afetado o cuidado em Enfermagem por meio do aumento da carga de trabalho, desempenho de múltiplos papéis dentro da instituição, complexidade do cuidado ao paciente, corte de equipe e insegurança no trabalho (Engel, 2004).

O estresse no ambiente de trabalho está relacionado a diversos fatores, como as condições de trabalho, o relacionamento 
interpessoal, gerenciamento de conflitos, estrutura e clima organizacional, natureza do trabalho, desenvolvimento da carreira e interface do trabalho com a vida pessoal. A Enfermagem, além de estar sujeita a esses fatores multidimensionais, ainda apresenta fatores como plantões de trabalho, relacionamento multidisciplinar, múltiplos papéis e expectativas, políticas institucionais, limitações de tempo e resistência física e emocional necessárias para o trabalho. A luta constante para manter o equilíbrio entre os fatores organizacionais e o cuidar no trabalho de Enfermagem, pode levar ao desgaste físico e emocional (Camelo, Angerami, 2008).

O profissional de Enfermagem geralmente possui mais de um vínculo empregatício em turnos diferentes, incompatíveis com o ciclo circadiano fisiológico, com pouco tempo destinado ao lazer e, como a maioria pertence ao gênero feminino, a jornada de trabalho doméstico também deve ser considerada. Esse estilo de vida agitado decorre, geralmente, de necessidades financeiras e manutenção de um padrão social, o que pode levar ao estresse. As relações interpessoais na equipe de saúde também são referidas como fator contribuinte para o estresse relacionado ao trabalho, assim como o ritmo e exigência das instituições (Silva, Melo, 2006).

A busca constante para equilibrar os fatores organizacionais e a assistência mobiliza os profissionais tanto emocionalmente, quanto física e espiritualmente. $\mathrm{Na}$ dimensão física, por exemplo, exposições repetidas e prolongadas às condições de estresse podem ocasionar tensão e fadiga. Psicologicamente, pode frequentemente provocar emoções como ansiedade, depressão, medo e raiva. Em resposta a esses sentimentos, comportamentos como compulsão alimentar, alcoolismo e tabagismo são utilizados como enfrentamento ao estresse. Espiritualmente, o estresse pode causar uma desconexão com a crença pessoal (Engel, 2004).

Quando os profissionais estão esgotados, emoções como medo e raiva podem desencadear reações de luta ou fuga. Para abordar a questão do estresse dos enfermeiros, são necessárias 
técnicas de gerenciamento e promoção de saúde no ambiente de trabalho (Engel, 2004).

No Brasil encontra-se uma representação grande de profissionais de Enfermagem nos hospitais. Os fatores relacionados ao ambiente, ergonomia e risco biológico geram tensão e ansiedade, principalmente quando a equipe de enfermagem está voltada ao cuidado de pacientes com doenças crônicas, traumas agudos, cuidados críticos e paliativos (Silva, Melo, 2006).

Por meio de um estudo quantitativo, transversal e descritivo, realizado em 2000 com 116 enfermeiros de dois hospitais no município de São Paulo, sendo um governamental e um beneficente, que trabalhavam em setores fechados (UTI, centro cirúrgico, centro obstétrico, centro de materiais, hemodiálise, hemodinâmica, berçário e endoscopia) e unidades abertas (unidade de internação, pronto atendimento, maternidade, controle de infecção hospitalar), verificouse os estressores presentes e os níveis de estresse desses profissionais nos diferentes tipos de unidade. Os enfermeiros que apresentaram maior nível de estresse foram os que trabalhavam em unidades abertas, principalmente em relação a atividades relacionadas à administração de pessoal, como controlar a equipe de enfermagem, realizar a distribuição de funcionários, supervisionar as atividades da equipe, entre outras (Bianchi, 2000).

Em contrapartida, em um estudo descritivo e exploratório com profissionais de Enfermagem de unidades de Internação e unidades especiais como UTI, Centro Cirúrgico (CC) e Pronto Socorro (PS) de um hospital privado na cidade de São Paulo, as autoras identificaram que os profissionais dos dois últimos setores citados apresentaram maiores índices de estado de ansiedade em relação às unidades de Internação e UTI. Fatores como estrutura de trabalho institucional, relações de poder e relacionamento, foram citados como influenciadores e facilitadores para a ocorrência de estresse (Gatti et. al., 2004). 
Outros estudos são necessários em diferentes instituições de saúde em âmbito nacional, portanto, a fim de avaliar o nível de estresse em enfermeiros e propor estratégias para sua redução e prevenção.

\subsection{AURICULOTERAPIA}

A acupuntura foi introduzida a partir do século VI nos países vizinhos à China e no século XVI/XVII, na Europa. Nas últimas décadas vem se difundindo por todo o mundo em função da crescente aceitabilidade, pelas comunidades científicas, após estudos realizados sob uma perspectiva moderna ocidental, com métodos científicos de investigação (Kurebayashi, Prado, 2011).

A orelha é mencionada no mais antigo livro de medicina chinês, o Clássico de Medicina Interna do Imperador Amarelo, publicado há 2000 anos atrás. O pavilhão auricular está relacionado com todas as partes do corpo humano e todos os meridianos convergem para a orelha. Em 1957, Paul Nogier, neurocirurgião francês, fez um estudo cuidadoso da orelha e das inervações auriculares, desenhando a figura de um feto invertido, correspondente ao formato da orelha (Figura 2), encontrando diferentes pontos para a estimulação neural e tratamento de diferentes doenças. A terapia através da orelha pode ser utilizada para o tratamento de enfermidades agudas e crônicas, doenças dolorosas inflamatórias, dependência química, doenças endocrinometabólicas, perturbações psíquicas como ansiedade, depressão, angústia e falta de concentração (Souza, 2001). 
Figura 2 - llustração do pavilhão auricular e imagem fetal. São Paulo, 2014.

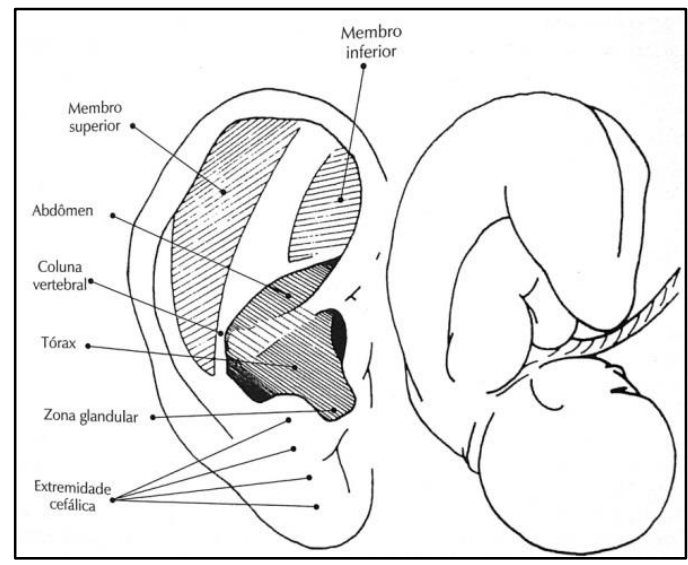

Fonte: Nogier, PMF. Noções Práticas de Auriculterapia. São Paulo: Andrei; 1998. p. 21.

Por meio do mapa do feto invertido e das prévias pesquisas de Nogier, cuja proposta era investigar as conexões neurofisiológicas entre pontos reflexos auriculares e o sistema nervoso central, os estudos sobre a ação da auriculoterapia começaram a tomar forma. Ele definiu a existência de 3 diferentes áreas no pavilhão que corresponderiam, na orelha externa, a diferentes tipos de inervação neuronal e categorias de tecido embrionário: a endodérmica, mesodérmica e a ectodérmica (Figura 3) (Kurebayashi, Prado, 2011).

Figura 3 - Áreas no pavilhão auricular segundo origem embriológica. São Paulo, 2014.

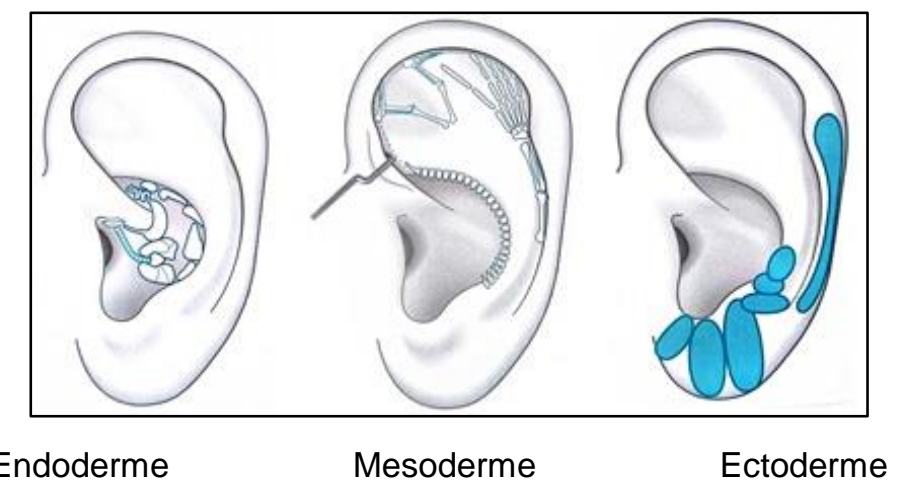

Fonte: Landgren K. Ear Acupuncture: a pratical guide. Philadelphia: Churchill Livingstone; 2008. p.51-52. 
As três principais inervações da orelha ocorrem através dos nervos: trigêmeo, vago e plexo cervical, que são responsáveis pelas áreas mesodérmica, endodérmica e ectodérmica, respectivamente (Figura 4).

Figura 4 - Principais inervações do pavilhão auricular. São Paulo, 2014.

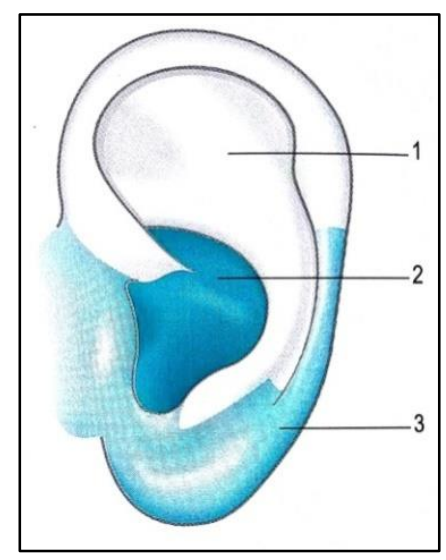

1: Nervo trigêmeo

2: Nervo vago

3: Plexo cervical

Fonte: Landgren K. Ear Acupuncture: a pratical guide. Philadelphia: Churchill Livingstone; 2008. p.57.

Há, atualmente, duas linhas de auriculoterapia. Uma derivada da escola francesa, que determina o microssistema auricular como reflexologia de uma ação neurológica conduzida pelo sistema parassimpático. Quando determinada área da cartilagem auricular é perfurada, estimula-se, a partir desse ponto, determinada área do cérebro, descarregando endorfinas que agirão no sistema corporal, acionando a liberação de um neurotransmissor. Já para escolha de pontos, a linha chinesa da auriculoterapia é baseada na concepção holística, nos princípios da Medicina Tradicional Chinesa (MTC) de que o corpo e ambiente são indissociáveis (Souza, 2001). O presente estudo seguiu o mapa chinês de auriculoterapia.

Devido aos desacertos em relação a nomenclaturas e posições de pontos auriculares, desde 1982 a Organização Mundial de Saúde (OMS) tem organizado, juntamente com outras 
instituições, a padronização de pontos de auriculoterapia. E em 1993, a Chinese Standard Ear-Acupoints estabeleceu 91 pontos principais adotados na China (Suen, Wong, Leung, 2001).

A técnica de estimulação dos pontos pode ser realizada por meio de diversos materiais como agulhas semipermanentes, sementes de mostarda, esferas de aço, esferas magnéticas, massagem, pressão, estimulação elétrica, entre outros. Antes da aplicação é necessário realizar a detecção do ponto, através da pressão, utilizando uma pinça ou instrumento de ponta romba. Espera-se que a estimulação gere dor à pressão ou crie uma depressão leve no local. Os pontos que se apresentam mais sensíveis à dor são considerados pontos reativos à estimulação e, portanto, pontos que podem apresentar melhores resultados terapêuticos (Souza, 2001).

Em seguida, realiza-se a antissepsia local com álcool 70\% e algodão. Com a pinça ou aplicador de agulhas auriculares, o ponto escolhido é puncionado perpendicularmente de forma rápida. Após aplicação, as agulhas são cobertas com fita adesiva hipoalergênica, permanecendo por, no máximo, sete dias (Souza, 2001).

Em relação aos ensaios clínicos em acupuntura, um grupo internacional de pesquisadores acupunturistas experientes desenvolveram recomendações para realização dos ensaios nessa área, STRICTA (Standards for Reporting Interventions in Controlled Trials of Acupunture), adaptado a partir da lista de verificação do CONSORT (Consolidated Standards of Reporting Trials). Essas recomendações procuram incorporar diferentes tipos e particularidades da acupuntura, desde pesquisas mais recentes aos estilos mais tradicionais, incluindo outras práticas comumente utilizadas em conjunto com a acupuntura. É recomendado que nestes ensaios clínicos exista um grupo controle, ou seja, um grupo de comparação. Este pode envolver um comparador ativo, tais como fisioterapia, ou procedimentos minimamente invasivos, como é o caso da acupuntura sham, utilizando pontos que não são indicados 
para o tratamento. Pode também ser grupo controle sem intervenção ou como lista de espera (MacPherson et. al., 2002).

Entretanto, a acupuntura sham invasiva ou não invasiva pode apresentar respostas circulatórias, imunológicas e neurofisiológicas, pois o mecanismo da acupuntura e da auriculoterapia não é totalmente conhecido. Particularmente em relação à auriculoterapia, outro viés dificulta a escolha por um delineamento de pesquisa: a existência de mais de um mapa desenvolvido e utilizado mundialmente. As duas principais linhas de pesquisa são derivadas da escola chinesa e francesa, conforme já referido, que embora apresentem algumas similaridades, apresentam estilos, conceitos e mapas divergentes. Isso dificulta a escolha de pontos verdadeiros e pontos sham (Hammerschlag, 1998). 
4 HIPÓTESE 


\subsection{HIPÓTESE NULA $\left(\mathrm{H}_{0}\right)$}

Auriculoterapia verdadeira apresentará igual redução dos níveis de estresse nos enfermeiros em relação à auriculoterapia sham.

\subsection{HIPÓTESE ALTERNATIVA $\left(\mathrm{H}_{1}\right)$}

Auriculoterapia verdadeira apresentará maior redução dos níveis de estresse nos enfermeiros em comparação com auriculoterapia sham. 
Ensaio Clínico Controlado Randomizado, simples-cego, com 3 grupos: Controle (sem nenhum tratamento), Auriculoterapia (com pontos indicados para estresse), Placebo (com pontos sham).

Para definição da amostra de participantes, foi realizado levantamento epidemiológico, com caracterização dos enfermeiros do Hospital Beneficência Portuguesa de São Paulo, Unidade São Joaquim, por meio da aplicação do questionário de avaliação de nível de estresse e ficha de dados sócio-demográficos. A coleta de dados foi realizada no período de Outubro de 2013 a Fevereiro de 2014.

Foi realizado cegamento para análise estatística. Os resultados foram entregues ao estatístico em forma de banco de dados sem denominar os grupos, identificados por meio de siglas.

\subsection{LOCAL DE ESTUDO}

A pesquisa foi realizada no Hospital Beneficência Portuguesa de São Paulo, maior complexo hospitalar privado da América Latina, fundado em 1859. É composto por três unidades, Hospital São Joaquim, Hospital São José e Hospital Santo Antônio. Atende mais de 1,5 milhão de pessoas por ano, tornando-se referência no atendimento médico hospitalar em diversas especialidades, como cardiologia, oncologia, neurologia, gastroenterologia, entre outras.

O estudo foi realizado na maior unidade do complexo, Hospital São Joaquim. Possui o selo de Acreditação Excelência (Nível 3) pela Organização Nacional de Acreditação (ONA). A instituição possui cerca de 6000 colaboradores, dentre os quais, 2700 compõem a equipe de Enfermagem.

\subsection{AMOSTRA}

Foram convidados a participar do estudo aproximadamente 290 enfermeiros dos 3 turnos e diversos setores. Dentre esses, 257 
aceitaram responder os questionários de estresse e sócio demográficos. Conforme ilustrado no fluxograma (Figura 5), 89 pessoas foram excluídas, 82 por apresentarem nível de estresse abaixo do critério de inclusão, 5 pessoas com nível acima e 2 pessoas comunicaram que estariam de férias no período.

A amostra foi constituída de 168 enfermeiros que apresentaram escore de estresse entre 40 a 110 pontos na Lista de Sintomas de Estresse (LSS) e, portanto, atenderam os critérios de inclusão. Optou-se por limitar a pontuação, correspondente ao nível médio e alto de estresse, pois poucas pessoas apresentaram nível altíssimo e, portanto, para obtenção de amostras homogêneas. Outros critérios de inclusão foram participação voluntária e disponibilidade para realização das sessões de auriculoterapia.

A partir dos critérios de inclusão, a randomização ou divisão aleatória dos participantes nos 3 grupos foi realizada em blocos, através do programa Random Allocation Software. O grupo Controle foi composto por 54 participantes, grupo Auriculoterapia por 58 e o Placebo por 56 participantes. Trinta e cinco pessoas descontinuaram o estudo, conforme o fluxograma, pelos seguintes motivos: 17 saíram de férias, 8 saíram de licença médica, 5 indisponíveis para realização das sessões ou avaliação, 3 desligaram-se da instituição, 1 ficou gestante e 1 começou a fazer uso de medicamento psicotrópico. 
Figura 5 - Fluxograma de participação dos enfermeiros. São Paulo, 2014.

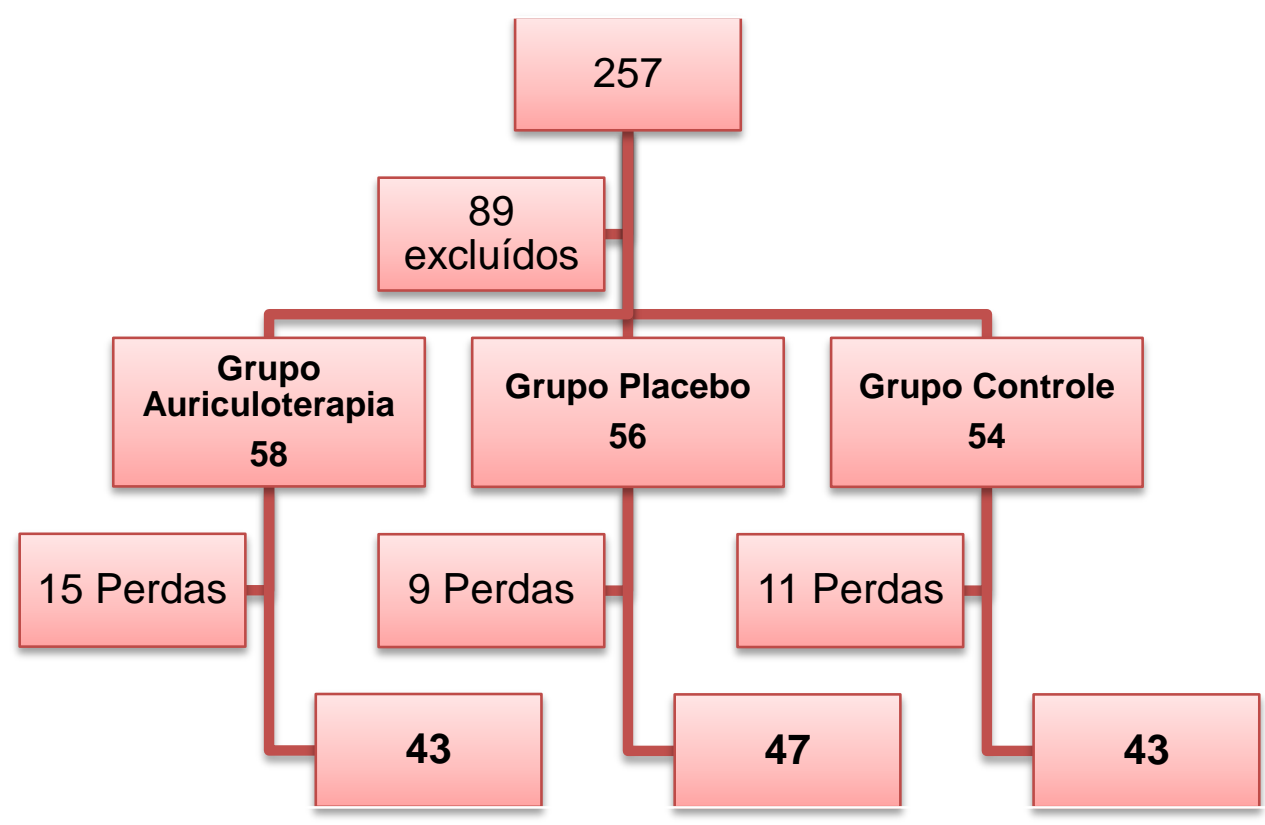

Fonte: Dados coletados pela autora.

Foram excluídas as gestantes, pois alguns pontos atuam sobre o útero e poderiam ser abortivos, portanto, a principal contraindicação é para as gestantes até o $3^{\circ}$ mês de gravidez (Souza, 2001); e aqueles que participavam de outra terapia energética ou qualquer outro tratamento para estresse no período do estudo.

A partir dos ensaios clínicos realizados com o mesmo delineamento em 2010 e 2011, que demonstraram que participantes com características similares apresentaram escore LSS com desvio padrão em torno de 25 unidades, e, considerando, portanto, como uma diferença clinicamente importante, 15 unidades do escore $(60 \%$ do desvio ou efeito de 0,6 ) entre os grupos Controle/Placebo contra Intervenção ao final do tratamento, estimou-se uma amostra mínima de 44 sujeitos por grupo, sob hipótese bicaudal, poder de $80 \%$ e nível de significância de 5\% (Chow, Shao, Wan, 2008). Ainda levando em consideração uma perda de acompanhamento de $20 \%$. 
Sugeriu-se uma amostra mínima inicial de 53 sujeitos por grupo, 159 no total.

\subsection{ASPECTOS ÉTICOS}

Por envolver seres humanos, o estudo atendeu à Resolução 466/2012 do Conselho Nacional de Saúde. Os dados somente começaram a ser coletados após aprovação pelo Comitês de Ética em Pesquisa da Escola de Enfermagem da Universidade de São Paulo sob o Processo n²52.931 (Anexo 1) e do Hospital Beneficência Portuguesa de São Paulo Parecer nº408.748 (Anexo 2), CAAE 12449413.9.0000.5392, explanação e consentimento dos sujeitos, mediante assinatura do Termo de Consentimento Livre e Esclarecido - TCLE (Apêndice A). O TCLE foi assinado em duas vias, sendo uma do participante e outra da pesquisadora. Somente a pesquisadora teve acesso à identidade e resultados de cada participante, como previsto no TCLE.

\subsection{INSTRUMENTOS DE COLETA DE DADOS}

Foi utilizado a Lista de Sintomas de Stress (LSS) (Anexo 3). O LSS é um instrumento de avaliação que consiste em uma lista de 59 sintomas psico-fisiológicos e psicossociais de stress, no qual o sujeito deve associar para cada sintoma uma das quatro respostas: nunca (0), poucas vezes (1), frequentemente (2) ou sempre (3). Os escores obtidos nas respostas são somados e fornecem o nível de stress do indivíduo. Este instrumento é resultado da associação entre uma lista elaborada por dois estudiosos (Vasconcellos, 1984) e o "Questionário de Stress do Psicólogo no Exercício Profissional" (Covolan, 1989). Nesse questionário a pontuação de 0 a 11 é considerada nula, 12 a 29 (nível baixo), 30 a 59 (nível médio), 60 a 120 (nível alto) e acima de 120, nível altíssimo. 
Foi solicitado o preenchimento de uma ficha com os seguintes dados pessoais: nome, idade, sexo, estado civil, telefone, e-mail, presença de gravidez, utilização de outro(s) tratamento(s) para estresse, tempo de formação, pós-graduação, setor, cargo, horário de trabalho, tempo de trabalho, carga horária semanal, trabalho em outra instituição (Apêndice B).

Para avaliação da percepção do estresse, foi utilizada uma Escala Visual Analógica (EVA) para nível de estresse, adaptada de Pafaro (2002) (Apêndice C). Nessa escala foi colocada uma linha na vertical, graduada de 0 a 10 , sendo 0 ausência de estresse e 10 estresse severo. Cada participante assinalava o nível de estresse que estava sentindo no momento, sendo de 0 a 3 nível baixo, 4 a 6 nível baixo e 7 a 10 nível alto de estresse.

\subsection{COLETA DE DADOS}

Os enfermeiros dos três turnos foram convidados a participar da pesquisa a partir da explanação feita pela pesquisadora, agendada previamente com cada gestora dos diversos setores do hospital. Os que manifestaram interesse responderam os instrumentos de coleta de dados, LSS, EVA e ficha de dados pessoais.

Após randomização, os participantes dos grupos auriculoterapia e placebo, receberam 12 sessões de auriculoterapia (2 sessões por semana) com duração de aproximadamente 5 minutos cada. As sessões foram agendadas previamente $\mathrm{e}$ realizadas individualmente. Exceto o grupo controle que não recebia sessões de auriculoterapia. Entretanto, aqueles que fizeram parte do grupo controle ou do grupo placebo receberam orientação ao final da pesquisa sobre sua condição e foram atendidos pelo mesmo tempo e número de sessões que os que participaram do grupo auriculoterapia, sem qualquer ônus para os mesmos. 
Todos os sujeitos que aceitaram participar do estudo foram avaliados quanto a níveis de estresse após 8 sessões, ao término de 12 sessões e 15 dias após o término das aplicações (follow-up), inclusive o grupo controle, que também realizou as avaliações com a mesma frequência que os demais.

Todas as aplicações foram feitas pela pesquisadora, enfermeira e acupunturista. Todos os custos da técnica de auriculoterapia foram de responsabilidade total da pesquisadora.

\section{Grupo Auriculoterapia}

$\mathrm{Na}$ Medicina Tradicional Chinesa (MTC) não há padronização no tratamento do estresse, por se tratar de doença multifatorial. Ressaltem-se os fatores limitantes de uma pesquisa relacionada à MTC, uma vez que a padronização de pontos em um tratamento pode subverter os princípios conceituais sobre os quais a MTC se estruturou. Para esta medicina, os elementos cosmológicos desempenham um papel importante na determinação das constituições individuais, enquanto que, para a racionalidade ocidental, sequer são considerados. Para a Ciência Médica, o objeto de estudo é a doença, sua identificação, sua etiologia e sua classificação. Para a MTC, a classificação das doenças toma por referência os sujeitos doentes e suas constituições individuais (São Paulo, 2002). Desta forma, a proposta de manter um protocolo de pontos foi feita para possibilitar a avaliação quantitativa, estatística do estudo científico, nos moldes ocidentais, controlado e aleatorizado, dos efeitos de determinados pontos sobre o pavilhão auricular e que sejam eficazes para diminuir os sinais e sintomas de estresse.

Protocolo utilizado neste grupo:

- Shen Men: localiza-se na fossa triangular, logo acima da bifurcação da raiz superior e inferior da antihélice. É um ponto usado no controle da ação excitatória e inibitória do córtex cerebral e tem efeito tranquilizante, analgésico e antialérgico (Souza, 2001). 
- Tronco Cerebral: situa-se no meio da incisura, na junção do antitrago com o antihélice, utilizado em afecções do cérebro, com função também de sedação (Souza, 2001).

Após a devida localização dos pontos reativos com um localizador de pontos, era realizada a antissepsia do pavilhão auricular com algodão e álcool a 70\%.

Os participantes foram orientados para a retirada das agulhas antes do período solicitado se houvesse desconforto excessivo ou prurido e sinais de alergia. Foi recomendado que 0 participante permanecesse de 2 a 3 dias com as agulhas, não havendo necessidade de estimular o local.

A escolha desses pontos deve-se ao fato de que estes mesmos foram utilizados em um estudo desenvolvido em 2011 e publicado em 2012, no qual auriculoterapia verdadeira com esses mesmos pontos diminuiu os níveis de estresse e ansiedade em estudantes de Enfermagem (Prado, Kurebayashi, Silva, 2012).

Esses pontos também foram utilizados em outro ensaio clínico controlado randomizado, publicado em 2012, que buscou avaliar os níveis de estresse na equipe de Enfermagem de um hospital e analisar a efetividade da auriculoterapia com agulhas e sementes. Os sujeitos foram randomizados em três grupos: controle, agulhas e sementes. Os dois últimos grupos receberam oito sessões nos pontos Shen Men, Tronco Cerebral e Rim. O instrumento de avaliação utilizado foi a Lista de Sintomas de Stress (LSS), aplicado no início, após quatro, oito sessões e follow-up de 15 dias. As autoras concluíram que a auriculoterapia foi eficaz na redução de estresse em profissionais de Enfermagem, com melhores resultados para agulhas do que para sementes, em escores altos, com manutenção de efeitos por 15 dias (Kurebayashi, Gnatta, Pavarini et. al., 2012). 


\section{Grupo Placebo}

Foram escolhidos dois pontos: um próximo à área da Bochecha, entre o quadrante IV e V do lóbulo, indicado para tratar paresia facial e neuralgia do trigêmeo; e outro nas imediações do ponto correspondente ao Ouvido Externo, no trago, indicado para tratamento de inflamações na parte externa da orelha, zumbido e déficit de audição. Ambos não deveriam ser responsivos à estimulação de pressão e dor, portanto, foram previamente testados com um apalpador antes de sua colocação (Hecker et. al., 2006).

Os pontos utilizados neste estudo estão redesenhados na Figura 6. As cores representam as diferentes áreas de inervação do pavilhão auricular.

Figura 6 - Áreas inervadas e pontos da pesquisa. São Paulo, 2014.

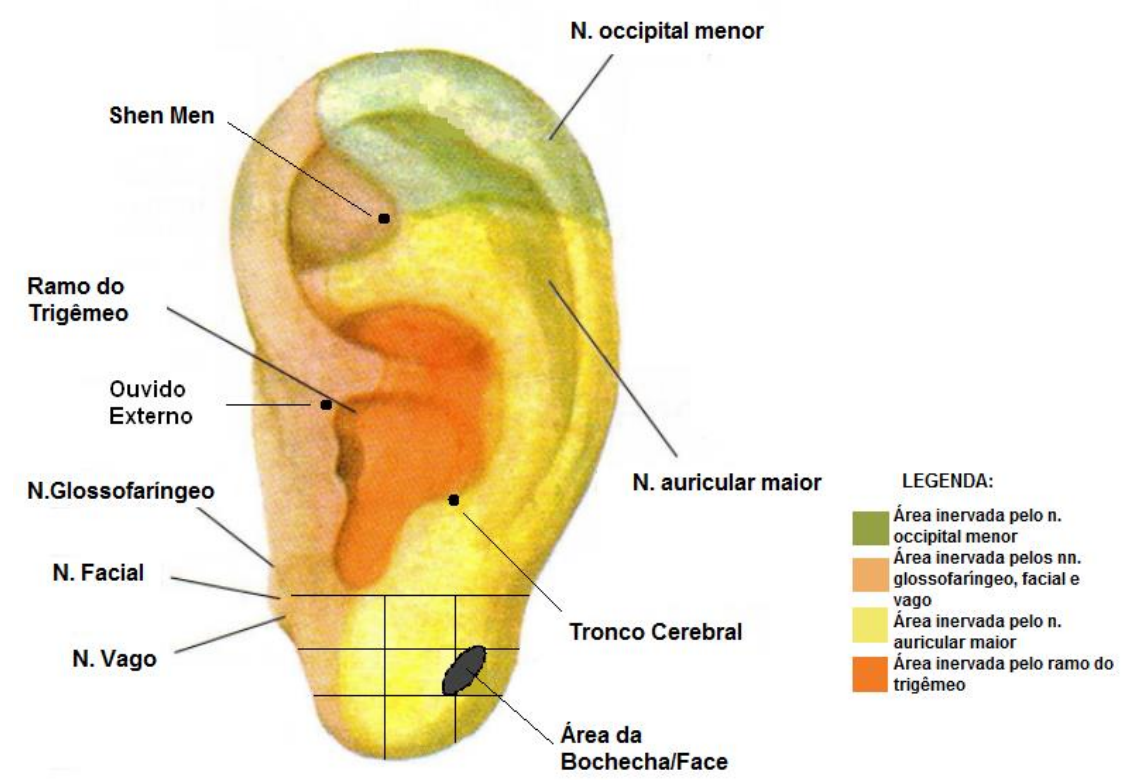

Fonte: Adaptado de Martins EIS, Garcia EG. Pontos de Acupuntura: Guia ilustrado de referência. São Paulo: Roca; 2003.

Foi tolerado, no máximo, perda de 3 sessões por sujeito, desde que não fossem consecutivas, pois a acupuntura pode apresentar bons resultados com no mínimo uma sessão por semana (Stux, Hammerschlag, 2005). 


\subsection{ANÁLISE ESTATÍSTICA}

Os dados foram submetidos a uma análise estatística descritiva. Foram calculados os valores de média e desvio-padrão para as variáveis quantitativas. Foi utilizada ANOVA de medidas repetidas de dois fatores $(3 \times 4)$, com teste Post hoc Tukey. Teste de Correlação de Pearson foi realizado para comparação entre EVA e LSS. Para avaliação da influência do setor, cargo e turno e os níveis de estresse foi utilizado regressão linear. Foi verificado o tamanho de efeito do tratamento pelo eta-quadrado.

Para todos os testes foi utilizado o programa estatístico R- v 2.12.2. 
6 RESULTADOS 


\subsection{DESCRITIVA DOS DADOS SÓCIO-DEMOGRÁFICOS}

Dos 257 enfermeiros que participaram do estudo, 233 eram mulheres $(91 \%)$ e $24(9 \%)$ homens.

Gráfico 1 - Distribuição dos participantes segundo sexo. São Paulo, 2014.

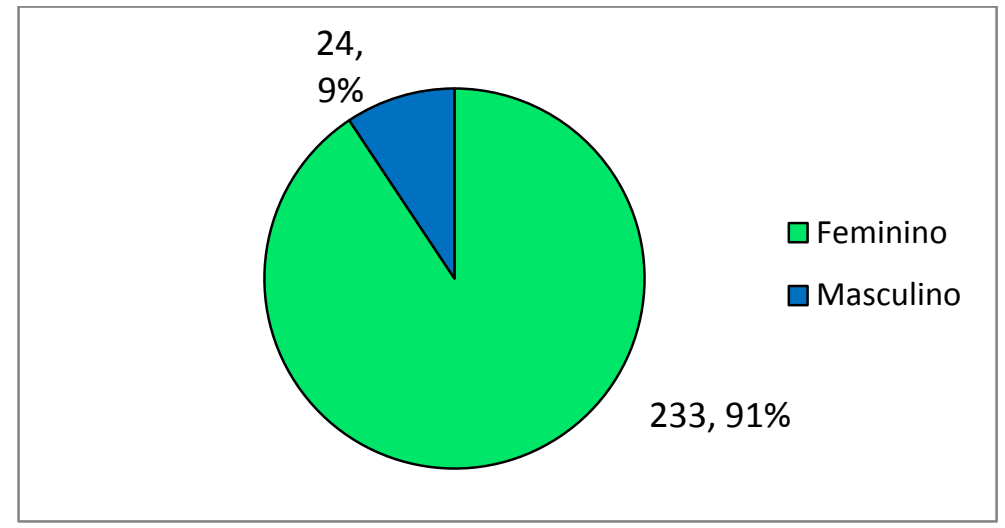

Fonte: Dados coletados pela autora.

Em relação ao estado civil, $122(47,47 \%)$ eram casados, 114 $(44,36 \%)$ solteiros, $18(7 \%)$ divorciados, $2(0,78 \%)$ viuvos e 1 $(0,39 \%)$ não informado.

Gráfico 2 - Distribuição dos participantes segundo estado civil. São Paulo, 2014.

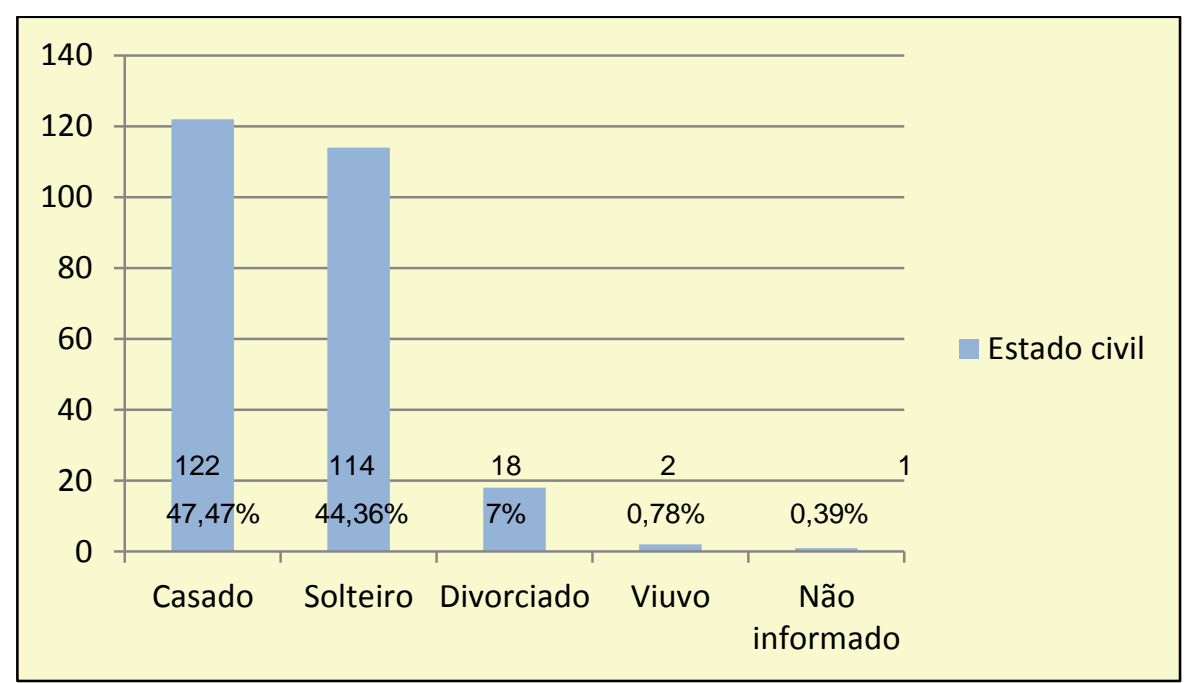

Fonte: Dados coletados pela autora. 
A média de idade dos participantes foi de 36,05 anos. A média de tempo de formação foi de 8,44 anos e de tempo de trabalho no setor foi de 3,92 anos (Tabela 1).

Tabela 1 - Média e Desvio Padrão das variáveis: Idade, Tempo de formado (anos), Tempo de trabalho no setor (anos). São Paulo, 2014.

\begin{tabular}{|c|c|c|c|c|c|}
\hline & $\mathbf{N}$ & Mínimo & Máximo & Média & DP \\
\hline Idade & 257 & 22 & 63 & 36,05 & 8,29 \\
\hline Tempo de formação & 257 & 0 & 41 & 8,44 & 7,82 \\
\hline $\begin{array}{l}\text { Tempo de trabalho } \\
\text { no setor }\end{array}$ & 257 & 0,04 & 30 & 3,92 & 5,69 \\
\hline
\end{tabular}

Duzentos e vinte e sete (88\%) enfermeiros apresentavam algum curso de pós-graduação e apenas 30 (12\%) não eram pósgraduados.

Gráfico 3 - Distribuição dos participantes segundo pós-graduação. São Paulo, 2014.

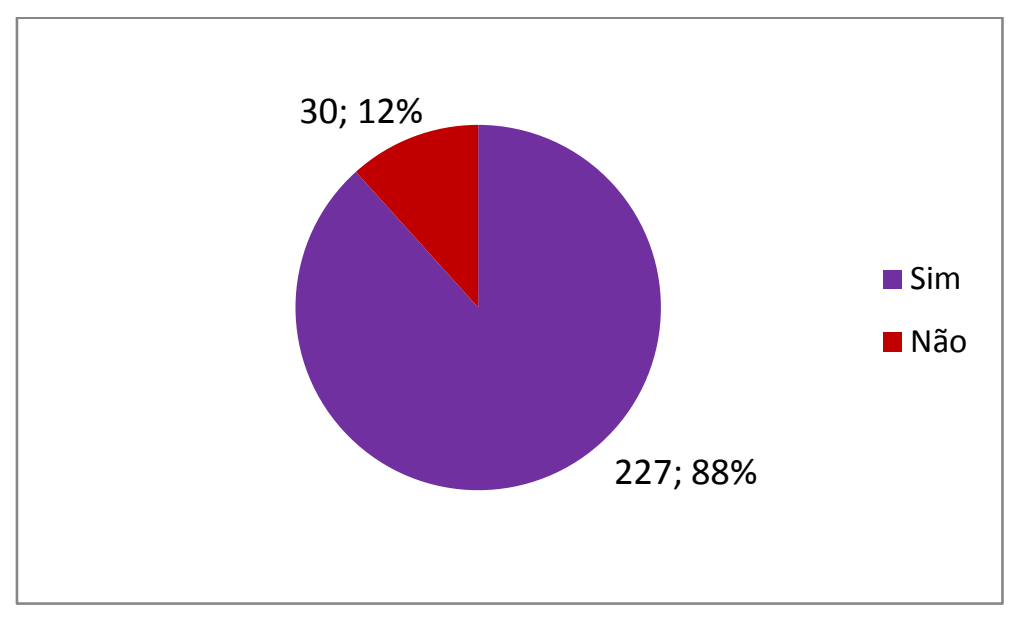

Fonte: Dados coletados pela autora.

A média de pontuação de LSS entre os tipos de cargos foi de 59,43 pontos para os enfermeiros com cargos administrativos e 54,59 pontos para os enfermeiros assistenciais (Tabela 2). Foram 
classificados como cargo administrativo, enfermeiros que não trabalhavam diretamente na assistência aos pacientes, ou seja, cargos de gerência, coordenação e supervisão, setores como Serviço de Controle de Infecção Hospitalar, Educação Continuada, Escola de Enfermagem, Métodos Gráficos e Clínicas externas e internas. Como cargo assistencial todos os enfermeiros que prestavam assistência direta aos pacientes, mesmo em setores onde existia a divisão de enfermeiro administrativo e assistencial, como em algumas unidades de internação e de terapia intensiva, pois embora exista essa divisão, os enfermeiros administrativos nesses setores não lidam apenas com atividades administrativas, mas também prestam cuidados aos pacientes.

Tabela 2 - Média e Desvio Padrão da pontuação de LSS dos tipos de cargos. São Paulo, 2014.

\begin{tabular}{lccc}
\hline \multicolumn{1}{c}{ Cargo } & N & Média & DP \\
\hline Administrativo & 54 & 59,43 & 30,54 \\
Assistencial & 203 & 54,59 & 27,02 \\
\hline
\end{tabular}

Fonte: Dados coletados no Hospital Beneficência Portuguesa de São Paulo.

$\mathrm{Na}$ tabela 3 encontram-se os percentuais dos participantes em cada nível de estresse segundo LSS. O nível de maior frequência foi o nível alto de estresse, 112 (43,58\%) enfermeiros apresentavam escore alto. 
Tabela 3 - Frequência e percentual dos participantes segundo níveis de estresse. São Paulo, 2014.

\begin{tabular}{lcc}
\hline Níveis de Estresse & $\mathbf{N}$ & $\%$ \\
\hline Nulo & 10 & 3,89 \\
Baixo & 39 & 15,18 \\
Médio & 94 & 36,58 \\
Alto & $\mathbf{1 1 2}$ & $\mathbf{4 3 , 5 8}$ \\
Altíssimo & 2 & 0,78 \\
Total & 257 & 100 \\
\hline
\end{tabular}

Fonte: Dados coletados no Hospital Beneficência Portuguesa de São Paulo.

Já os percentuais de participantes com níveis de estresse segundo EVA (baixo, médio e alto) estão descritos na Tabela 4 a seguir. $O$ escore predominante segundo EVA foi a faixa de pontuação de 4 a 7 , correspondente ao nível médio de estresse $(57,59 \%)$.

Tabela 4 - Frequência e percentual de participantes segundo níveis de estresse pela Escala Visual Analógica (EVA). São Paulo, 2014.

\begin{tabular}{lcc}
\hline \multicolumn{1}{c}{ EVA } & N & $\%$ \\
\hline Baixo (0-3) & 58 & 22,57 \\
Médio (4-7) & $\mathbf{1 4 8}$ & $\mathbf{5 7 , 5 9}$ \\
Alto (8-10) & 42 & 16,34 \\
Não informado & 9 & 3,5 \\
Total & 257 & 100 \\
\hline Fonte: Dados coletados no Hospital Beneficência Portuguesa de São Paulo.
\end{tabular}

Em todos os turnos de trabalho (Manhã, Tarde, Noite e horário comercial) o nível de estresse mais frequente foi Nível Alto, conforme explicitado na Tabela 5. 
Tabela 5 - Distribuição dos participantes nos turnos de trabalho segundo os níveis de estresse. São Paulo, 2014.

\begin{tabular}{lcccccccccc}
\hline & Manhã & $\%$ & Tarde & $\%$ & Noite & $\%$ & Comercial & $\%$ & NI & Total \\
\hline Nulo & 1 & 1,06 & 5 & 5,68 & 2 & 5,71 & 2 & 5,13 & - & 10 \\
Baixo & 12 & 12,77 & 19 & 21,59 & 5 & 14,29 & 3 & 7,69 & - & 39 \\
Médio & 38 & 40,43 & 30 & 34,09 & 10 & 28,57 & 15 & 38,46 & 1 & 94 \\
Alto & 42 & $\mathbf{4 4 , 6 8}$ & 34 & $\mathbf{3 8 , 6 4}$ & 18 & $\mathbf{5 1 , 4 3}$ & 18 & $\mathbf{4 6 , 1 5}$ & - & 112 \\
Altíssimo & 1 & 1,06 & - & - & - & - & 1 & 2,56 & - & 2 \\
TOTAL & 94 & 100 & 88 & 100 & 35 & 100 & 39 & 100 & 1 & 257 \\
\hline
\end{tabular}

$\mathrm{NI}=$ não informado.
Fonte: Dados coletados no Hospital Beneficência Portuguesa de São Paulo.

Os setores do hospital foram classificados em 3 categorias: administrativo, unidade aberta ou unidade fechada. O Departamento de Enfermagem, Escola de Enfermagem, Serviço de Controle de Infecção Hospitalar, Educação Continuada, Métodos Gráficos, Clínicas Externas e Internas foram classificados como setores administrativos, pois os enfermeiros que trabalhavam nesses setores não estavam diretamente ligados à assistência aos pacientes. Já as unidades de internação pediátricas e de adultos foram classificadas como Unidades Abertas. As unidades de terapia intensiva adulto e pediátricas, Pronto Socorro, Centro Cirúrgico, Central de Materiais Esterilizados, Hemodiálise e Hemodinâmica foram classificados como Unidades Fechadas.

Os enfermeiros que trabalham nos setores administrativos ou que possuem cargos de chefia apresentaram média de pontuação de estresse mais elevada em comparação com os profissionais que atuam na assistência, conforme descrito na Tabela 6, a seguir. Entre as áreas assistenciais, os enfermeiros que trabalham em unidades de internação apresentaram média maior do que aqueles que trabalham em setores fechados. 
Tabela 6 - Frequência dos participantes, média e desvio padrão da pontuação de estresse segundo tipos de setores. São Paulo, 2014.

\begin{tabular}{lccc}
\hline \multicolumn{1}{c}{ Setor } & N & Média & DP \\
\hline Administrativo & 54 & 59,43 & 30,54 \\
Unidades abertas & 124 & 56,44 & 27,50 \\
Unidades fechadas & 70 & 51,70 & 26,15 \\
TOTAL & 257 & 55,61 & 27,80 \\
\hline
\end{tabular}

Fonte: Dados coletados no Hospital Beneficência Portuguesa de São Paulo.

Os plantões no Hospital Beneficência Portuguesa de São Paulo são de 8 horas diárias, com carga horária semanal de 40 horas para os enfermeiros que estão na assistência e, em alguns setores administrativos, 44 horas semanais. Esse dado difere da maioria dos hospitais, cuja carga horária semanal é de 36 horas e plantões de 6 horas ou escala de 12/36h. Além da carga horária semanal mais elevada, $32(12,45 \%)$ trabalhavam também em outra instituição. A maior parte $(6,23 \%)$ com carga horária de 76 horas semanais e apenas um trabalhava 84 horas semanais, conforme dados da Tabela 7 . 
Tabela 7 - Distribuição dos participantes que trabalham ou não em outra instituição, segundo carga horária semanal. São Paulo, 2014.

\begin{tabular}{|c|c|c|c|c|c|c|c|c|c|c|}
\hline $\begin{array}{l}\text { Trabalha } \\
\text { em outra } \\
\text { instituição }\end{array}$ & $\begin{array}{l}40 h \\
(\%)\end{array}$ & $\begin{array}{l}44 h \\
(\%)\end{array}$ & $\begin{array}{l}54 \mathrm{~h} \\
(\%)\end{array}$ & $\begin{array}{l}60 h \\
(\%)\end{array}$ & $\begin{array}{l}70 h \\
(\%)\end{array}$ & $\begin{array}{l}76 h \\
(\%)\end{array}$ & $\begin{array}{l}80 h \\
(\%)\end{array}$ & $\begin{array}{l}84 h \\
(\%)\end{array}$ & $\begin{array}{c}\text { Não } \\
\text { informado } \\
(\%)\end{array}$ & $\begin{array}{l}\text { Total } \\
\text { N (\%) }\end{array}$ \\
\hline Não & $\begin{array}{c}190 \\
(73,93 \%)\end{array}$ & $\begin{array}{c}35 \\
(13,62 \%)\end{array}$ & & & & & & & & $\begin{array}{c}225 \\
(87,55 \%)\end{array}$ \\
\hline Sim & & $\begin{array}{c}1 \\
(0,38 \%)\end{array}$ & $\begin{array}{c}2 \\
(0,78 \%)\end{array}$ & $\begin{array}{c}2 \\
(0,78 \%)\end{array}$ & $\begin{array}{c}4 \\
(1,56 \%)\end{array}$ & $\begin{array}{c}16 \\
(6,23 \%)\end{array}$ & $\begin{array}{c}4 \\
(1,56 \%)\end{array}$ & $\begin{array}{c}1 \\
(0,38 \%)\end{array}$ & $2(0,78 \%)$ & $\begin{array}{c}32 \\
(12,45 \%)\end{array}$ \\
\hline Total & $\begin{array}{c}190 \\
(73,93 \%)\end{array}$ & 36 (14\%) & $\begin{array}{c}2 \\
(0,78 \%)\end{array}$ & $\begin{array}{c}2 \\
(0,78 \%)\end{array}$ & $\begin{array}{c}4 \\
(1,56 \%)\end{array}$ & $\begin{array}{c}16 \\
(6,23 \%)\end{array}$ & $\begin{array}{c}4 \\
(1,56 \%)\end{array}$ & $\begin{array}{c}1 \\
(0,38 \%)\end{array}$ & $2(0,78 \%)$ & $\begin{array}{c}257 \\
(100 \%)\end{array}$ \\
\hline
\end{tabular}

Fonte: Dados coletados no Hospital Beneficência Portuguesa de São Paulo. 
Dentre os 257 participantes, 155 (60,31\%) não apresentavam problemas de saúde e 102 (39,69\%) apresentavam alguma queixa. As mais frequentes foram dores osteomusculares, seguidas de enxaqueca/cefaleia, HAS, Hipotireoidismo, Gastrite, Dislipidemia, DM, entre outras.

Durante a explanação e convite para participar do estudo foram explicados os critérios de exclusão, portanto, os enfermeiros que faziam uso de algum medicamento psicotrópico ou outra prática complementar não responderam aos instrumentos de coleta. Não foi investigado o uso de demais medicamentos prescritos ou utilizados como auto medicação.

Quanto aos sintomas que compõem a Lista de Sintomas de Stress, o mais frequente foi o de número 5: "No final de um dia de trabalho, sinto-me desgastado", com 94,16\% dos participantes assinalando esse item, sendo que $66,15 \%$ dos enfermeiros relataram esse sintoma atribuindo maior nota na escala de 0 a 3 , correspondente a frequência "Sempre". O sintoma que apareceu em menor frequência, apenas em 9,34\% dos participantes, foi o número 32: "Fumo demais".

Dos 257 enfermeiros que participaram do estudo, apenas 17 $(6,6 \%)$ relataram outros sintomas que não faziam parte da LSS. Os sintomas listados foram: vontade de chorar por qualquer motivo (7 participantes), dificuldade de concentração, tontura, tensão prémenstrual, espasmos palpebrais, baixa autoestima, câimbras (2 participantes), tricotilomania, dermatite atópica, fogachos e sudorese (1 participante cada).

\subsection{ANÁLISE INTERGRUPOS E EVOLUÇÃO DOS NÍVEIS DE ESTRESSE SEGUNDO A LSS E EVA}

Para comparação entre os grupos constatou-se diferença estatisticamente significante $(p<0,001)$, assim como para 
comparação entre os momentos de avaliação $(p<0,001)$ e a interação entre os fatores grupo e avaliação $(p<0,001)$.

Na Tabela 8 estão descritas as médias e desvio padrão dos escores de estresse pela LSS segundo os três grupos.

Quanto ao resultado do teste de ANOVA para medidas repetidas, constatou-se que não houve diferença entre os momentos de avaliação do nível de estresse no Grupo Controle. Já nos Grupos Auriculoterapia e Placebo, houve diferença significativa entre os momentos de avaliação.

No Post Hoc de Tukey observou-se que, no Grupo Auriculoterapia, a diferença se deu entre a primeira avaliação (LSS 1 ) e as demais $(p<0,001)$, ou seja, ou tratamento apresentou efeito após 8 sessões e manteve-se constante com 12 sessões e no follow-up de 15 dias. Em contrapartida, no Grupo Placebo, a diferença estatisticamente significativa só ocorreu entre a primeira e terceira avaliação, ou seja, após 12 sessões de auriculoterapia e se manteve no follow-up.

Tabela 8 - Média e desvio padrão dos escores da LSS dos grupos experimentais em cada avaliação. São Paulo, 2014.

\begin{tabular}{|c|c|c|c|c|}
\hline Grupo (N) & $\begin{array}{c}\text { LSS } 1 \\
\text { Média (DP) }\end{array}$ & $\begin{array}{c}\text { LSS } 2 \\
\text { Média } \\
\text { (DP) }\end{array}$ & $\begin{array}{l}\text { LSS } 3 \\
\text { Média } \\
\text { (DP) }\end{array}$ & $\begin{array}{c}\text { LSS } 4 \\
\text { Média } \\
\text { (DP) }\end{array}$ \\
\hline Controle (54) & $\begin{array}{c}66,59 \\
(17,77)\end{array}$ & $\begin{array}{c}70,65 \\
(25,15)\end{array}$ & $\begin{array}{c}68,57 \\
(25,38)\end{array}$ & $\begin{array}{c}66,79 \\
(27,60)\end{array}$ \\
\hline $\begin{array}{l}\text { Auriculoterapia } \\
\qquad(58)\end{array}$ & $\begin{array}{c}72,47 \\
(19,47)^{\star}\end{array}$ & $\begin{array}{c}51,90 \\
(21,32)\end{array}$ & $\begin{array}{c}48,24 \\
(20,47)\end{array}$ & $\begin{array}{c}51,40 \\
(16,43)\end{array}$ \\
\hline Placebo (56) & $\begin{array}{c}66,98 \\
(17,91)^{a, b}\end{array}$ & $\begin{array}{c}54,31 \\
(23,25)\end{array}$ & $\begin{array}{c}44,20 \\
(23,50)^{\mathrm{a}}\end{array}$ & $\begin{array}{c}41,30 \\
(26,81)^{\mathrm{b}}\end{array}$ \\
\hline
\end{tabular}


O gráfico 4 ilustra a evolução dos três grupos quanto aos níveis de estresse.

Gráfico 4 - Evolução do escore de estresse entre os grupos ao longo das avaliações. São Paulo, 2014.

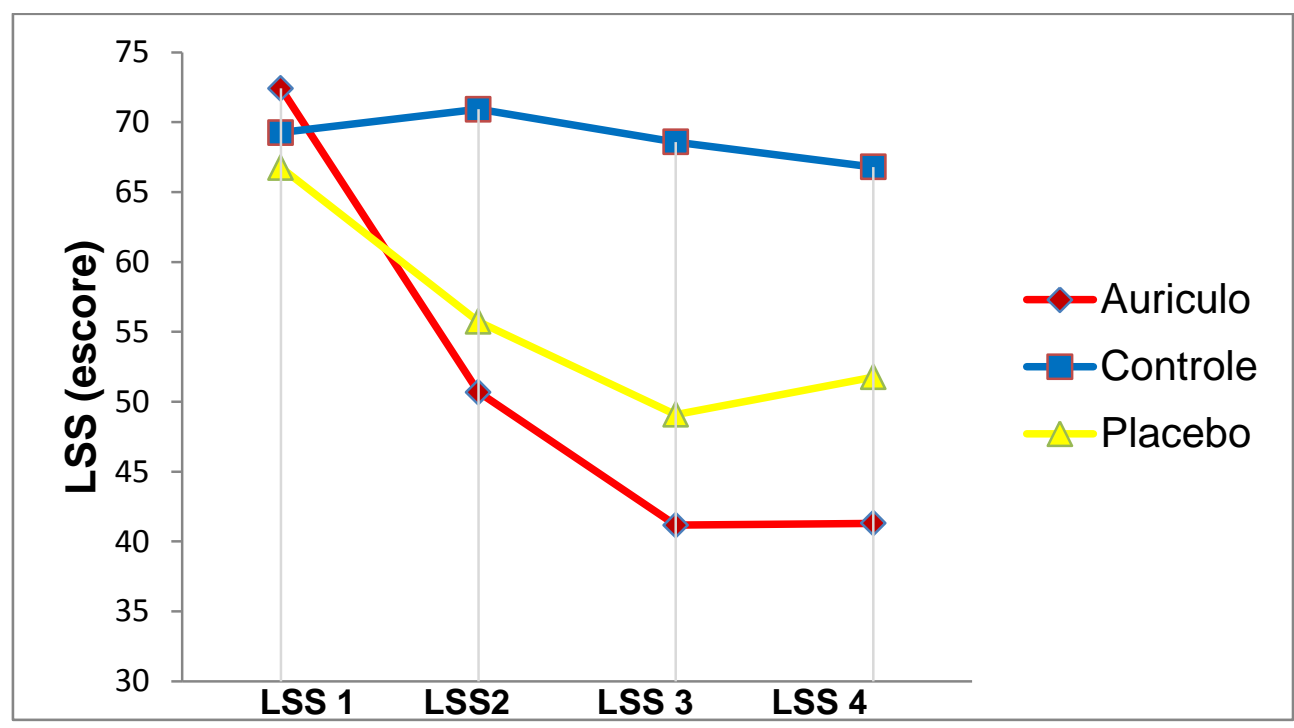

Ao avaliar o tamanho de efeito pelo eta-quadrado, observouse que o Grupo Auriculoterapia apresentou melhor resultado com redução dos níveis de estresse em $34 \%$ de efeito de tratamento contra 8\% do Grupo Placebo.

\subsection{TESTE DE CORRELAÇÃO ENTRE LSS E EVA}

$\mathrm{Na}$ análise de Correlação de Pearson entre os instrumentos LSS e EVA obteve-se índice de 0,57. Na primeira avaliação a correlação entre LSS e EVA foi bastante fraca $(0,33)$. No segundo momento com 8 sessões foi de 0,57, seguido de 0,61 na terceira avaliação e 0,60 no follow-up. Essa situação demonstra a dificuldade inicial na auto percepção dos sintomas de estresse, que melhorou ao longo da coleta de dados. 


\subsection{REGRESSÃO LINEAR ENTRE OS NÍVEIS DE ESTRESSE E CARGO, SETOR E TURNO DE TRABALHO}

Ao avaliar a influência do cargo, não foi possível afirmar que o tipo de cargo influencia na variância do escore de estresse pela LSS $(p=0,257)$, assim como o tipo de setor $(p=0,261)$ e turno de trabalho $(p=0,10)$.

Há uma pequena tendência do turno da tarde apresentar nível de estresse menor que os demais turnos, porém não é estatisticamente significante. 
A amostra do estudo foi composta por 257 enfermeiros, predominantemente do sexo feminino (91\%), com média de idade de 36,05 anos, perfil semelhante a demais estudos (Guido et al., 2011; Lima et al., 2012; Menzani, Bianchi, 2009).

A Enfermagem é conhecida não apenas por caracterizar-se como uma profissão essencialmente feminina, como também pela especificidade das ações desenvolvidas no dia-a-dia. No ambiente de trabalho, as profissionais gerenciam o desenvolvimento de suas atividades e, fora desse contexto, gerenciam suas vidas como pessoas, esposas e mães. Essa situação, de desenvolver múltiplas atividades, com vínculos de trabalho formais ou não, pode também contribuir para o desenvolvimento do estresse (Menzani, Bianchi, 2009).

A média de tempo de formação foi de 8,44 anos e de tempo de trabalho no setor foi de 3,92 anos, ou seja, apesar de não trabalharem por período prolongado em suas unidades, eram graduados há mais tempo.

A maioria dos enfermeiros (88\%) apresentava algum curso de pós-graduação. Essa característica tem sido observada entre enfermeiros jovens, que já buscam especializar-se em suas áreas de interesse, para melhor inserção e diferenciação na área hospitalar.

Segundo Elias e Navarro (2006), o ambiente hospitalar é reconhecido como insalubre, penoso e perigoso para os que ali trabalham, um local propício para o adoecimento. Além dos riscos de acidentes e doenças de ordem física aos quais esses profissionais estão expostos, o sofrimento psíquico é também bastante comum, diante da alta pressão e cobrança a que estão submetidos.

Dos 257 enfermeiros participantes, 43,58\% apresentavam nível alto de estresse. Em todos os turnos de trabalho houve predominância do nível alto. No turno noturno, mais de 50\% dos enfermeiros apresentavam essa classificação.

O efeito do trabalho em turnos para a saúde dos profissionais de enfermagem pode se manifestar através dos sintomas de 
estresse, principalmente, distúrbios neuropsíquicos, cardiovasculares e gastrintestinais. Além disso, interfere na vida pessoal e familiar do profissional, pela dificuldade de participação de atividades sociais e planejamento de vida (Costa, Morita, Martinez, 2000).

Encontrou-se outro estudo, do tipo exploratório, cujo objetivo era determinar o nível de stress, hardiness e as suas correlações com o trabalho nos diferentes turnos para enfermeiros de um hospital escola. Verificou-se que os enfermeiros que não possuíam horário de trabalho fixo, trabalhavam em horário comercial ou eram do turno noturno apresentaram alerta para alto nível de stress, sendo que os enfermeiros do turno noturno apresentaram os menores valores para hardiness controle e desafio (Batista, Bianchi, 2013).

As ações mais técnicas e socialmente mais qualificadas são realizadas pelas enfermeiras, responsáveis pela chefia, coordenação e supervisão do trabalho dos técnicos e dos auxiliares de enfermagem que, por sua vez, executam o trabalho menos qualificado, dedicando mais tempo aos pacientes (Elias, Navarro, 2006).

Entre os enfermeiros que trabalhavam em horário comercial e, portanto, apresentavam cargos administrativos, 46,15\% apresentavam nível alto de estresse. O trabalho do enfermeiro, inserido nas instituições de saúde, é muitas vezes multifacetado, dividido e submetido a uma diversidade de cargos que são geradores de desgaste. Os enfermeiros são responsáveis por pessoas, o que os obriga a um maior tempo de trabalho dedicado à interação, aumentando a probabilidade de ocorrência do estresse por conflitos interpessoais (Guerrer, Bianchi, 2008).

Para os cargos administrativos, a média de pontuação de LSS foi de 59,43 pontos. Já para os enfermeiros que estavam diretamente ligados à assistência ao paciente foi de 54,59 pontos. 
Este resultado também foi encontrado no estudo realizado por Guerrer e Bianchi (2008), onde os enfermeiros assistenciais apresentaram índice elevado de estresse nos domínios assistência de enfermagem e coordenação da unidade. Já para aqueles com cargos de chefia, o índice de estresse foi elevado para os domínios relacionamento, funcionamento da unidade e administração de pessoal. A média total do nível de estresse entre os cargos foi maior para aqueles com cargos de chefia e coordenação.

Os profissionais de enfermagem que cuidam de outras pessoas, muitas vezes se esquecem de cuidar de si mesmos e do ambiente de trabalho, e por isso, tem adoecido pelas condições e pelos ambientes desfavoráveis para desenvolver as suas atribuições (Ribeiro et. al., 2012).

Cento e dois enfermeiros (39,69\%) apresentavam alguma queixa de saúde. $O$ problema mais frequente foram dores osteomusculares. Das doenças ocupacionais, os distúrbios musculoesqueléticos são um dos mais graves e são considerados importante problema de saúde. Os principais fatores de risco são a organização do trabalho e as possíveis sobrecargas de segmentos corporais em determinados movimentos, como por exemplo, força excessiva para realizar algumas tarefas, repetitividade e posturas inadequadas (Magnago et al., 2010).

Corroborando ainda com o presente estudo, Leite, Silva e Merighi (2007) também verificaram que a principal queixa das profissionais de Enfermagem estava relacionada ao sistema osteomuscular. Outro estudo, realizado por Borges (2013), verificou a eficácia da massagem para tratamento da lombalgia entre a equipe de Enfermagem de um Pronto Socorro localizado na Grande São Paulo. Foi realizado por meio de um ensaio clínico randomizado, utilizando a massagem por acupressão e técnica a laser como placebo para o tratamento da lombalgia ocupacional. Os profissionais que receberam a massagem apresentaram redução do escore de dor de moderada para leve e também melhora quanto à 
avaliação funcional relacionada à lombalgia, mostrando-se uma terapêutica eficaz para tratamento desse tipo de dor.

Os enfermeiros que trabalhavam em setores administrativos apresentaram média de estresse mais elevada $(59,43)$. Entre as unidades assistenciais abertas e fechadas, os enfermeiros que trabalhavam em setores fechados apresentaram menor nível de estresse $(51,7)$ em comparação com os de setores abertos como unidades de internação $(56,44)$.

Em consonância ao resultado encontrado nessa pesquisa, França et. al. (2012), realizaram um estudo para identificar a Síndrome de Burnout em profissionais de enfermagem de dois hospitais. Ao analisar os tipos de setores, verificaram que os profissionais que trabalhavam no setor administrativo eram os mais acometidos. No universo administrativo, o enfermeiro responsável responde diretamente pelas Resoluções exigidas pelo Conselho de Enfermagem e atribuições definidas por órgão superior e, dessa forma, os níveis de exigência acarretam para o profissional um conjunto de condições que podem resultar na Síndrome de Burnout. Apesar dos ambientes fechados serem carregados de atribuições e responsabilidades que levam o profissional a sofrer fortes influências de estressores, ainda nesse estudo, os setores abertos apresentaram maior índice em comparação com os fechados.

A Unidade de Terapia Intensiva (UTI) é considerada uma unidade fechada, cujo entrosamento com outros setores é bastante limitado. É um setor onde se encontram pacientes internados que necessitam de cuidados intensivos diretos. A assistência prestada a pacientes em setores críticos é bastante polêmica, pois de um lado ela requer intervenções rápidas, de outro, mobilizam emoções e sentimentos de forma muito intensa. Nesses setores, o trabalho do enfermeiro é permeado por ambiguidades, aspectos gratificantes e limitantes que estão presentes no seu mundo e na vida (Guerrer, Bianchi, 2008). 
Outro estudo que corrobora com esses resultados é de Bianchi (2000) que verificou que os enfermeiros de unidades abertas apresentavam maior nível de estresse do que em setores fechados. Os enfermeiros de unidades de internação estão sujeitos a um desgaste emocional. A autora discute também a correlação com sobrecarga de trabalho, tarefas repetitivas e monótonas e volume de atividades burocráticas existente levando-os à falta de controle das atividades realizadas, perda de energia, fadiga e esgotamento.

Em contrapartida, Myhren, Ekeberg e Stokland (2013) avaliaram a relação entre o nível de satisfação no trabalho, estresse ocupacional e sintomas de burnout em médicos e enfermeiras intensivistas de um hospital universitário. A média de satisfação no trabalho entre os enfermeiros foi menor do que entre os médicos intensivistas. Escores médios de Burnout foram relativamente baixos, porém o escore alto foi correlacionado com personalidade vulnerável, baixa satisfação no trabalho e alto escore de estresse ocupacional.

Esses apontamentos acerca do estresse do enfermeiro continuam sendo levantados até a presente década. Os enfermeiros apresentam como um dos fatores de estresse o relacionamento interpessoal com os pacientes no hospital, como verificado em outro estudo publicado por Kato (2014). Este estudo avaliou a associação entre as estratégias de enfrentamento de 204 enfermeiros hospitalares para lidar com o estresse interpessoal com os pacientes e o estresse psicológico em comparação com um grupo de vendedores. Os enfermeiros apresentaram maior angústia e sofrimento psíquico do que o grupo controle composto pelos vendedores. A autora discorre sobre a importância do coping construtivo na comunicação e relacionamento interpessoal enfermeiro-paciente. Essa estratégia de enfrentamento construtiva envolve esforços ativos para melhorar, manter ou sustentar um relacionamento por meio de uma comunicação eficaz, pois apesar da relação com os pacientes ser um fator potencial de estresse, 
também é visto como fator de satisfação no trabalho e pode reduzir o estresse dos enfermeiros.

Em relação à EVA, a fraca correlação entre LSS e EVA na primeira avaliação $(0,33)$ pode ser explicada pelo desconhecimento da sintomatologia do estresse pela maioria dos profissionais. $O$ mesmo ocorreu no estudo de Pafaro (2002), no qual obteve autoavaliação sem estresse dos profissionais de Enfermagem que apresentavam sintomas de estresse.

O sintoma mais frequente e que apareceu com maior intensidade foi o relacionado ao desgaste após um dia de trabalho. Sempre haverá desgaste psicológico mesmo que o trabalho seja físico ou manual (Hanzelmman, Passos, 2010). No caso das atividades do enfermeiro, o trabalho não é apenas braçal, mas envolve aspectos emocionais, mentais, gerenciais e que exigem o raciocínio clínico e crítico a todo instante. Dessa forma, o trabalho possui aspectos negativos que afetam tanto o corpo físico quanto a mente do indivíduo.

Hanzelmman e Passos (2010) realizaram um estudo descritivo, qualitativo, a fim de identificar as representações sobre os fatores desencadeadores do estresse ocupacional e sua influência no trabalho, atribuídos pelos profissionais de Enfermagem. Os fatores identificados pelos participantes do estudo foram relacionados às condições e à organização do trabalho e os mesmos interferem, respectivamente, no corpo e na mente dos indivíduos.

Quanto ao tratamento para o estresse dos enfermeiros, observou-se que 0 Grupo Auriculoterapia obteve melhores resultados desde a segunda avaliação, após 8 sessões e mantevese até o final do estudo. Já o Grupo Placebo apresentou melhora somente a partir da terceira avaliação, após 12 sessões.

Outros estudos encontrados utilizaram os pontos Shen Men e Tronco Cerebral para redução de estresse e ansiedade. Um deles, publicado em 2009, realizado com profissionais da equipe de Enfermagem em uma unidade de terapia intensiva de um hospital 
privado na cidade de São Paulo, avaliou os níveis de estresse antes e após tratamento com auriculoterapia. Os resultados mostraram que os sintomas apresentados foram: desgaste, dores nas costas, comer em excesso, cansaço. Entre os profissionais, 85,4\% apresentou melhora dos sintomas após tratamento. As autoras concluíram que a auriculoterapia pode contribuir para a diminuição de sinais e sintomas de estresse (Giaponesi, Leão, 2009).

Como citado anteriormente, outro ensaio clínico realizado com profissionais de Enfermagem, utilizou os mesmos dois pontos, acrescidos do ponto Rim para diminuição do nível de estresse, obtendo resultados favoráveis (Kurebayashi et al., 2012).

O Ponto Shen Men também foi utilizado no estudo de Kurebayashi (2013) para tratamento do estresse em profissionais de Enfermagem. A autora trabalhou com um grupo protocolo, com pontos pré-determinados, incluindo os Pontos Shen Men e Tronco Cerebral e um grupo sem protocolo, cujos pontos foram escolhidos de acordo com os diagnósticos da Medicina Tradicional Chinesa. Em ambos os grupos utilizou-se o Ponto Shen Men em 100\% dos participantes.

Apesar da dificuldade em estabelecer pontos sham para auriculoterapia, devido à alta responsividade e inervação, a escolha dos pontos sham no presente estudo foi adequada. Os pontos Ouvido Externo e Área da Face apresentaram baixo efeito de tratamento (8\%) para redução do estresse entre os enfermeiros.

Todos esses estudos obtiveram bons resultados para o tratamento do estresse ou da ansiedade utilizando como um dos pontos de tratamento o Ponto Shen Men, já descrito nos diferentes mapas auriculares como eficaz para o tratamento dessas desordens.

\subsection{LIMITAÇÕES DO ESTUDO}

A primeira limitação do estudo foi relacionada ao tempo para desenvolvimento da pesquisa, desde os problemas técnicos para 
submissão nos dois Comitês de Ética (EEUSP e Hospital) até a aprovação pelo hospital. Para atingir a amostra mínima necessária, optou-se por fazer o recrutamento em dois momentos, sendo que a coleta de dados do segundo grupo recrutado coincidiu com as datas comemorativas de final de ano, época em que ocorre mudança na quantidade de pacientes que frequentam à instituição e a escala de trabalho também se encontra reduzida.

Outra limitação do estudo foi a realização das sessões por apenas uma terapeuta, que, apesar da padronização da técnica, pode apresentar o viés do terapeuta, levando em consideração a necessidade de replicação do estudo em populações distintas. 
8 CONCLUSÃO 
A amostra foi composta por 257 enfermeiros do maior hospital privado da América Latina, localizado na cidade de São Paulo. O nível de estresse prevalente em todos os turnos de trabalho foi o nível alto, com $43,58 \%$ dos participantes. Os enfermeiros com cargos administrativos apresentaram média de 59,43 de nível de estresse, enquanto que os enfermeiros assistenciais apresentaram média de 54,59 pontos na LSS.

Os resultados encontrados neste presente estudo permite afirmar que os pontos Shen Men e Tronco Cerebral foram eficazes para redução do estresse em enfermeiros com 8 sessões de auriculoterapia, 12 sessões e com follow up de 15 dias ( $p<0,001$ em todos os momentos). Além disso, os pontos selecionados como pontos sham, Ouvido Externo e Área da Bochecha/Face, podem ser utilizados como pontos placebos em novos estudos de estresse.

A auriculoterapia pode ser uma estratégia para reduzir o estresse desses profissionais, nos diversos setores, turnos e cargos, a fim de proporcionar melhor enfrentamento às situações de estresse no ambiente hospitalar. Faz-se necessário as instituições pensarem em estratégias para minimizar o estresse dos profissionais e proporcionar condições favoráveis para os enfermeiros realizarem suas atribuições de modo eficaz e saudável, levando-se em consideração que esses profissionais são responsáveis pelo cuidado de outro ser humano e também apresentam a necessidade de serem cuidados. 
9 REFERÊNCIAS 
Antoniazzi AS, Dell'Aglio DD, Bandeira DR. O conceito de coping: uma revisão teórica. Estud Psicol. 1998;3(2):273-294.

Batista KM, Bianchi ERF. A relação stress, hardiness e turno de trabalho em enfermeiros de um hospital de ensino. Enfermeria Global. № 29. 2013. 281-287.

Bianchi ERF. Enfermeiro hospitalar e o stress. Rev da Esc Enf USP. 2000;34(4):390-4.

Bianchi ERF. Escala Bianchi de Stress. Rev Esc Enferm USP. 2009;43(esp):1055-62.

Borges AMB, Carlotto MS. Síndrome de Burnout e fatores de estresse em estudantes de um curso técnico de enfermagem. Aletheia. 2004;19:45-56.

Borges TP. Uso da massagem como intervenção na lombalgia ocupacional em trabalhadores de enfermagem. [Dissertação]. São Paulo (SP): Universidade de São Paulo; 2013.

Brasil. Ministério da Saúde. Aprova a Política Nacional de Práticas Integrativas e Complementares (PNPIC) no Sistema Único de Saúde. Portaria 971 de 3 de maio de 2006. Disponível em: <http://dtr2001.saude.gov.br/sas/PORTARIAS/Port2006/GM/GM971.htm> Acesso em: 26 de Abril 2014.

Camelo SHH, Angerami ELS. Riscos psicossociais no trabalho que podem levar ao estresse: uma análise da literatura. Cienc Cuid Saude. 2008;7(2):232-240.

Cardoso A. Stress no trabalho. 2ํe. ed. Rio de Janeiro: Revinter; 2001.

Chow SC, Shao J, Wan H. Sample size calculations in Clinical Research. 2 ${ }^{\mathrm{a}}$ ed. Florida (USA): Champman \& Hall. CRC Biostatistical Series; 2008.

Conselho Federal de Enfermagem (COFEN). Resolução COFEN197/1997. Estabelece e reconhece as Terapias Alternativas como especialidade e/ ou qualificação do profissional de Enfermagem. In: Conselho Regional de Enfermagem de São Paulo (COREn-SP). Documentos básicos de enfermagem: enfermeiros, técnicos, auxiliares. São Paulo; 2001:159-60.

Conselho Federal de Enfermagem (COFEN). Resolução COFEN 290/2004. Fixa as Especialidades de Enfermagem. In: Conselho Regional de Enfermagem. Legislação. São Paulo (SP); 2004. 
Costa, ALS. Análise do stress nas situações de vida diária e do préoperatório imediato de pacientes cirúrgicos urológicos. [Dissertação]. São Paulo(SP): Escola de Enfermagem, Universidade de São Paulo; 1997.

Costa, ALS. Processos de enfrentamento do estresse e sintomas depressivos em pacientes portadores de retocolite ulcerativa idiopática. [Tese]. São Paulo(SP): Escola de Enfermagem, Universidade de São Paulo; 2003.

Costa ES, Morita I, Martinez MAR. Percepção dos efeitos do trabalho em turnos sobre a saúde e a vida social em funcionários da enfermagem em um hospital universitário do Estado de São Paulo Cad. Saúde Pública. 2000;16(2):553-555.

Covolan MA. O stress ocupacional do psicólogo clínico: Seus sintomas, suas fontes e as estratégias utilizadas para controlá-lo. [Dissertação]. Campinas(SP): Instituto de Psicologia, Pontifícia Universidade Católica de Campinas; 1989.

Elias MA, Navarro VL. A relação entre o trabalho, a saúde e as condições de vida: negatividade e positividade no trabalho das profissionais de enfermagem de um hospital escola. Rev Latino-am Enfermagem. 2006;14(4):517-25.

Engel B. Are we out of our minds with nursing stress? Creat Nurs. 2004;4:4-6.

Ferreira LRC, Martino MMF. O estresse do enfermeiro: análise das publicações sobre o tema. Rev. Ciênc. Méd. Campinas. 2006;15(3):241-248.

França FM, Ferrari R, Ferrari DC, Alves ED. Burnout e os aspectos laborais na equipe de enfermagem de dois hospitais de médio porte. Rev. Latino-Am. Enfermagem. 2012;20(5):[09 telas].

Gatti MFZ, Leão ER, Silva MJP, Puggina ACG. Comparação entre os níveis de ansiedade e stress apresentados e percebidos pela equipe de enfermagem. Rev Enfermería Global. 2004;3(2):1-12.

Giaponesi ALL, Leão ER. A auriculoterapia como intervenção para redução do estresse da equipe de enfermagem em terapia intensiva. Nursing (São Paulo). 2009;12(139):575-579.

Guerrer FJL, Bianchi ERF. Caracterização do estresse nos enfermeiros de unidades de terapia intensiva. Rev Esc Enferm USP. 2008; 42(2):355-62. 
Guido LeA, Linch GF, Pitthan LeO, Umann J. Stress, coping and health conditions of hospital nurses. Rev Esc Enferm USP. 2011;45(6):1434-9.

Hammerschlag R. Methodological and ethical issues in clinical trials of acupuncture. J Atern Complement Med. 1998;4:159-171.

Hanzelmann RS, Passos JP. Imagens e representações da enfermagem acerca do stress e sua influência na atividade laboral. Rev Esc Enferm USP. 2010;44(3): 694-701.

Hecker HU, Strittmatter B, Steveling A, Peuker ET. Topography and Indications of Auricular Acupuncture Points According to Regions. In: Hecker HU, Steveling A, Peuker ET. Microsystems Acupuncture. New York; 2006:37-127.

Juster RP, Bizik G, Picard M, Arsenault-Lapierre G, Sindi S, Trepanier $L$, et. al. A transdisciplinary perspective of chronic stress in relation to psychopathology throughout life span development. Dev Psychopathol. 2011;23:725-776.

Kato T. Coping with interpersonal stress and psychological distress at work: comparison of hospital nursing staff and salespeople. Psychology Research and Behavior Management. 2014; (7):31-36.

Kurebayashi LFS, Prado JM. Auriculoterapia e Enfermagem. In: Salles LF, Silva MJP (org.). Enfermagem e as Práticas Complementares em Saúde. São Caetano do Sul: Yendis; 2011,7796.

Kurebayashi LFS, Gnatta JR, Borges TP, Belisse G, Coca S, Minami A, et. al. Aplicabilidade da auriculoterapia com agulhas e sementes para diminuição de estresse em profissionais de enfermagem. Rev Esc Enf USP. 2012;46(1):89-95.

Kurebayashi LFS. Auriculoterapia chinesa para redução de estresse e melhoria de qualidade de vida de equipe de enfermagem: ensaio clínico randomizado. [Tese de Doutorado]. São Paulo (SP): Universidade de São Paulo; 2013.

Landgren K. Ear Acupuncture: a pratical guide. Philadelphia: Churchill Livingstone; 2008.

Leite PC, Silva A, Merighi MAB. A mulher trabalhadora de enfermagem e os distúrbios osteomusculares relacionados ao trabalho. Rev Esc Enferm USP. 2007; 41(2):287-91. 
Lima GF, Simonetti SH, Bianchi ERF, Kobayashi RM. Caracterización del estrés de enfermeros que trabajan en hospital especializado en cardiologia. Enfermeria Global. 2012;28:90-104.

Lipp MN. Pesquisas sobre o stress no Brasil. Campinas: Papirus; 1996.

Lipp MEN. Manual do Inventário de sintomas de stress para adultos. São Paulo: Casa do Psicólogo; 2000.

Lipp MEN, organizadora. Mecanismos neuropsicofisiológicos do Stress: teoria e aplicações clínicas. São Paulo: Casa do Psicológo; 2010.

Lundeberg T, Lund I, Sing A, Näslund J. Is placebo acupuncture what it is intended to be? eCAM. 2009: 1-5. Acesso em: 08 de Março de 2014. Disponível em: <http://ecam.oxfordjournals.org>.

MacPherson H, White A, Cummings M, Jobst KA, Rose K, Niemtzow RC. Standards for Reporting Interventions in Controlled Trials of Acupuncture: The STRICTA Recommendations. J Altern Complement Med. 2002;8(1):85-89.

Magnago TSBS, Lisboa MTL, Griep RH, Kirchhof ALC, Guido LA. Aspectos psicossociais do trabalho e distúrbio musculoesquelético em trabalhadores de enfermagem. Rev. Latino-Am. Enfermagem. 2010;18(3):140-147.

Martins EIS, Garcia EG. Pontos de Acupuntura: Guia ilustrado de referência. São Paulo: Roca; 2003.

Menzani G, Bianchi ERF. Stress dos enfermeiros de pronto socorro dos hospitais brasileiros. Rev. Eletr. Enf. [Internet]. 2009;11(2):32733. Disponível em <http://www.fen.ufg.br/revista/v11/n2/v11n2a13.htm> Acesso em: 02 de Maio de 2014.

Myhren $\mathrm{H}$, Ekeberg $\mathrm{O}$, Stokland $\mathrm{O}$. Job Satisfaction and Burnout among Intensive Care Unit Nurses and Physicians. Critical Care Research and Practice. 2013. Disponível em <http://dx.doi.org/10.1155/2013/786176> Acesso em: 01 de Junho de 2014.

Murofuse NT, Abranches SS, Napoleão AA. Reflexões sobre estresse e Burnout e a relação com a enfermagem. Rev Latino-am Enfermagem. 2005;13(2):255-61.

Nakai LS. Eficácia da auriculoterapia na diminuição dos níveis de estresse e ansiedade de adultos saudáveis. Trabalho de Conclusão 
de Curso de Graduação em Fisioterapia. São Paulo(SP): Universidade de São Paulo; 2007.

Pafaro RC. Estudo do estresse do enfermeiro com dupla jornada de trabalho em um Hospital de Oncologia Pediátrica de Campinas. [Dissertação]. Campinas(SP):Universidade Estadual de Campinas; 2002.

Prado JM, Kurebayashi LF, Silva MJP. Efficacy of auriculotherapy for the reduction of stress in nursing students: a randomized clinical trial. Rev Lat Am Enfermagem. 2012;20(4):727-35.

Ribeiro RP, Martins JT, Marziale MHP, Robazzi MLCC. O adoecer pelo trabalho na enfermagem: uma revisão integrativa. Rev Esc Enferm USP. 2012;46(2):495-504.

Rocha GF, Silva MJP. Eficácia da auriculoterapia na redução de sinais e sintomas de estresse e ansiedade. Trabalho de Conclusão de Curso de Graduação em Enfermagem. São Paulo(SP): Universidade de São Paulo; 2011.

São Paulo (Cidade). Secretaria Municipal de Saúde. Caderno Temático em Medicina Tradicional Chinesa [texto na internet]. São Paulo; 2002. [citado 2006 out. 16]. Acesso em: 01 de Maio de 2014. Disponível em: $<$ www.prefeitura.sp.gov.br//arquivos/secretarias/saúde/áreas_temati cas/0047/MTC_CadernoTematico.pdf>

São Paulo (Cidade). Lei no 13.717, de 08 de Janeiro de 2004. Dispõe sobre a implantação das terapias naturais na Secretaria Municipal de Saúde. São Paulo(SP);2004. Acesso em 01 de Maio de $2014 . \quad$ Disponível em: <http://www3.prefeitura.sp.gov.br/cadlem/secretarias/negocios_juridi cos/cadlem/integra.asp?alt=09012004L\%20137170000>.

Silva JLL, Melo ECP. Estresse e implicações para o trabalhador de enfermagem. Informe-se em promoção da saúde. 2006;2(2):16-18.

Souza MP. Tratado de Auriculoterapia. Brasília: Look Gráfica, 2001.

Stux G, Hammerschlag R. Acupuntura Clínica: Bases Científicas. Trad. Harly Winckler. Baueri (SP): Manole, 2005.

Suen LKP, Wong TKS, Leung AWN. Is there a place for auricular therapy in the realm of nursing? Complement Ther Nurs Midwifery. 2001;7:132-9. 
Vasconcellos EG. Stress coping und Soziale Kompentens bei Kardiovaskularen Erkrankungen. [Tese de Doutorado]. Alemanha: Ludwig Maximmilians Universitat; 1984. 


\section{APÊNDICE A}

\section{Termo de Consentimento Livre e Esclarecido}

Declaro que estou ciente dos procedimentos envolvidos na pesquisa "Aplicação da Auriculoterapia Verdadeira e Sham no Tratamento de Estresse em Enfermeiros" e que todos os dados e informações por mim concedidos serão sigilosos, não sendo revelada a minha identificação, ao final da pesquisa que será divulgada em dissertação, evento e em periódico da área. Estou ciente de que este trabalho tem como objetivos identificar os níveis de estresse dos enfermeiros e verificar a eficácia da auriculoterapia para o tratamento de estresse, e que os critérios de participação são: a minha participação voluntária, não estar grávida e ter preenchido os instrumentos de coleta de dados: a Lista de Sintomas de Stress (LSS), ficha de dados pessoais e Escala Analógica Visual (EAV). O presente estudo apresenta risco mínimo, pois envolve questionamentos cotidianos elementares que, em momento algum causarão desconforto ao participante. Fui informado(a) de que haverá uma divisão em grupos e que o Grupo Controle não fará nenhum tratamento, inicialmente. Para aqueles que forem sorteados para os Grupos Auriculoterapia e Placebo haverá 12 sessões de tratamento, 2 vezes por semana, durante 1 mês e 2 semanas e as sessões durarão em média 10 minutos. Os participantes dos três grupos responderão aos questionários (LSS e EAV) após 1 mês do início da pesquisa, após 1 mês e meio do início e 15 dias após o término do estudo.

Entendo que a minha participação ininterrupta durante este período é garantia para a obtenção dos resultados buscados pela pesquisa. Porém, estou informado de que poderei apresentar até 3 faltas não consecutivas ou desistir a qualquer momento da pesquisa, sem qualquer ônus material ou moral. Em caso de dúvidas ou mal estar, poderei ligar para pesquisadora. Os sujeitos que apresentarem 
alguma resposta não desejável como coceira, dor, incômodo ao toque e vermelhidão na orelha, poderão receber assistência no Instituto de Terapia Integrada e Oriental, situado na Rua Vieira Fazenda, ㄲo80, Vila Mariana, telefone 5575-4251.

A pesquisadora se compromete a oferecer o mesmo tratamento para os participantes da pesquisa que não participarem do Grupo Auriculoterapia pelo mesmo número de sessões e tempo, aplicando os mesmos pontos utilizados no Grupo Auriculoterapia, sem ônus para o sujeito ao término da pesquisa, no Instituto de Terapia Integrada e Oriental.

Declaro que, após convenientemente esclarecido(a) pela pesquisadora, consinto voluntariamente em participar da presente pesquisa, conforme as condições descritas. O termo presente será feito em duas vias, sendo uma do sujeito do estudo.

São Paulo, de , 2013.

Responsável pela coleta de dados: Juliana Miyuki do Prado Orientadora: Prof ${ }^{\underline{a}}$ Dr $^{\mathrm{a}}$ Maria Julia Paes da Silva E-mail para contato do Comitê de Ética em Pesquisa da Escola de Enfermagem da Universidade de São Paulo: edipesq@usp.br Telefone do Comitê de Ética em Pesquisa da Escola de Enfermagem da Universidade de São Paulo: (11) 3061-7548 E-mail do responsável pela pesquisa: jumiyuki@yahoo.com.br Telefone do responsável pela pesquisa (Juliana): (11) 99589-9877. Escola de Enfermagem São Joaquim: Ramal 5553/5555. 


\section{APÊNDICE B}

\section{Ficha de dados pessoais}

Nome:

Idade:

Sexo: $F($ ) $M($ ) Telefone:

Tempo de formado:

Cursos de Pós Graduação: ( ) Não ( ) Sim:

Setor:

Ramal: Horário de trabalho:

Cargo: ( ) Administrativo ( ) Assistencial

Tempo de trabalho como enfermeiro neste setor:

Trabalha em outra instituição: Sim( ) Não( ) Quanto tempo:

Carga horária semanal:

Estado civil: Solteiro/a( ) Casado/a( ) Divorciado/a( ) Viúvo/a( )

E-mail:

Doença pregressa: HAS( ) DM( ) Dor( ) Local:

Outras: Nenhuma doença( )

Presença de gravidez: Sim( ) Não( )

Utilização de outro(s) tratamento(s) para estresse e uso de medicamento(s) psiquiátrico(s): Sim( ) Não( )

Quais: 


\section{APÊNDICE C}

\section{Escala Analógica Visual}

Marque na linha abaixo o nível de estresse que você está sentindo no momento.

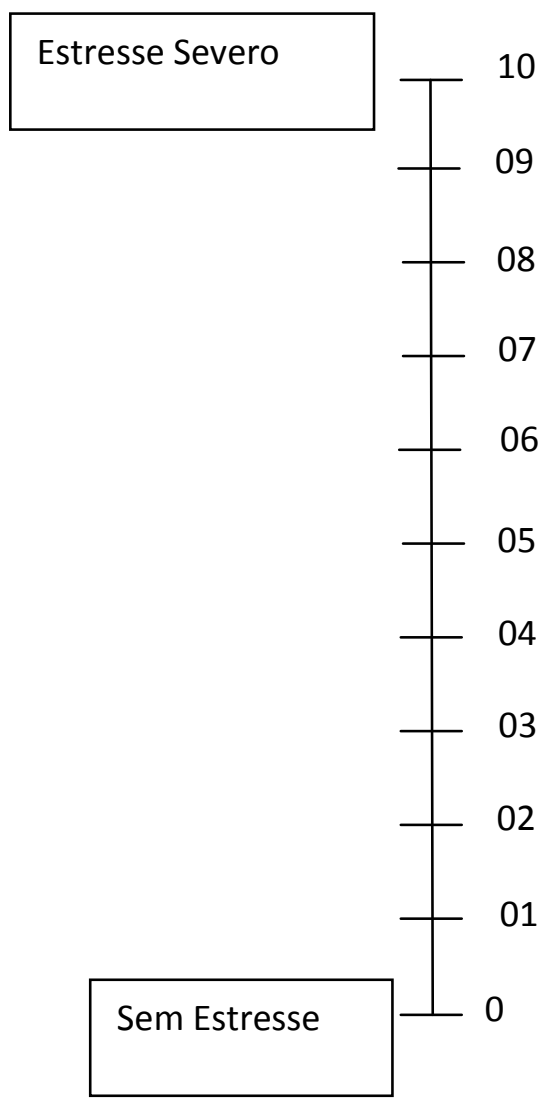




\section{ANEXO 1}

\section{ESCOLA DE ENFERMAGEM DA UNIVERSIDADE DE SÃO PAULO - EEUSP}

\section{PARECER CONSUBSTANCIADO DO CEP}

\section{DADOS DO PROJETO DE PESQUISA}

Titulo da Pesqulsa: Aplicaçắo da auriculoterapla verdadel ra e sham no tratamento de estresse em enfermel ros

Pesqulaador: Julana Mlyuk do Prado

Área Tematica:

Versas: 2

CAAE: 12449413.9 .0000 .5392

Instutulçäo Proponente: Escola de Enfermagem da Universidade de Säo Paulo - EEUSP

Patrocinador Principal: Financlamento Proprio

\section{DADOS DO PARECER}

Nümero do Parecer: 252.931

Data da Relatorla: 09/04/2013

Apresentsçaso do Projeto:

Este projeto de pesquisa tem como tnaldade a dssertaçăo de mestrado da proponente, 500 orlentaçấ da Profa Dra Marla Julla Paes da Silva. Consıstira na aplcaçăo da auriculoterapla verdadeira e sham no tratamento de estresse em enfermelros atuantes no Hosptal Beneflcencia Portuguesa de Sto Paulo. Tratase de um Ensalo Cilnico Controlado Randomizado, com 3 grupos: controle (sem nenhum tratamento), Intervençăo (auriculoterapla)e grupo placebo (com pontos sham). Fase 1: Aplicaçäo dos questionarios de avalaçăo de nivels de estresse e denniçăo da amostra de participartes. Fase 2:Randonizaçăo ou diviş̄o aleatoria dos participantes a partir dos criterios de inclusáo de escores de estresse pela Lista de Sintomas de Stress (LSS), com divistోo em 3 grupos por sortelo. O LSS e um instrumento de avallaçăo que consiste de uma lista de 59 sintomas psico-islologlcos e psicossocials de stress, no qual o sujehto deve associar para cada sintoma uma das quatro respostas: nunca (0). poucas vezes (1), frequentemente (2) ou sempre (3). Os escores obtidos nas respostas sao somados e fornecem o nivel de stress do indlviduo. Nesse questionario a pontuaç5o de 0 a 11 e considerada nula, 12 a 29 (nlvel baixo), 30 a 59 (nlvel medlo), 60 a 120 (nivel alto) e acima de 120 , nivel altissimo. A0s participantes sera solldtado o preenchimento de uma ficha de dados pessoals e a Escala Analogica Visual. Realizar-se-a o cegamento para analise estatistica. Os resultados serajo entregues ao estatistico em forma de banco de dados sem denominaçato dos grupos, Identificados por melo de siglas. Serdo sujeltos do estudo $\infty$ enfermeiros que aceltarem participar voluntariamente; que tenham disponilolidade de

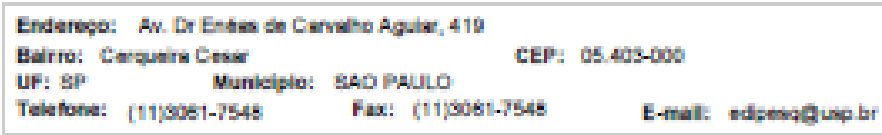




\section{ESCOLA DE ENFERMAGEM DA UNIVERSIDADE DE SÄO PAULO - EEUSP}

horario para realzaçăo das sessbes de auricuioterapla e que tenham escore de estresse entre entre 40 a 110 pontos no questionario LSS. A proponente esclarece que optou por IImitar a pontuaciajo, correspondente ao nivel medio e alto de estresse, para obter amostras homoge ineas. Serajo crite into de exclusa; 0 : enfemeirss gestantes ate o tercelro mes de gravidez, pols alguns pontos atuam soore o ujtero e poderiam ser abortlvos e partcipar de outro tratamento para estresse nesse peri $i$ odo. A pesquisadora tera $i$ acesso $a_{i}$ identldade e ao resultado dos questonarios LSS dos participantes, mas como previsto no Termo de Consentimento Llvre e Esclarecido (TCLE), a Identidade e resultados de cada participante ficarăo preservados para a pubilcaçáo e exposiçăo dos resutados da pesquisa. Os pronsslonals serąi o convidados a partcipar da pesquisa a partr da explanaçáo felta pela pesquisadora no Departamento de Entermagem do Hospital durante a passagem de plantáo dos enfermeiros e 05 que manifestarem interesse realizardo 05 testes para averiguar se possuem escores minimos para participar da pesqulsa. Aqueles que fizerem parte do grupo controle ou do grupo placebo recebera; o orientaçăo ao fnal da pesqulsa sobre sua condlçăo e serdo atendidos pelo mesmo tempo e numero de $5 e s 0_{\text {C }}$ es que forem atendidos os que participarem do gupo intervençấ, sem qualquer onus para 05 mesmos. Todos 05 sujeltos que aceitarem participar serăo avaliados quanto a nivels de estresse antes, apo is 8 sesso ies, ao te imino das 12 sessdes e 15 dlas apos o termino das aplicaçasos. O tratamento consistira em 12 sesso ies de auriculoterapla ( 2 sesso ies por semana) com durac $i_{i}{ }^{\circ}$ de aproximadamente 10 minutos cada. As sesso ${ }_{i}$ es sera ${ }^{\circ} \circ$ agendadas previamente e reallzadas Indlvidualmente. Exceto o grupo controle que na $i 0$ recebera $i s e s s o_{i}$ es de aurculoterapla. Todas as aplicac $i O_{i}$ es serajo felizs pela pesquisadora, enfermelra e acupunturita. Grupo de Intervençăo (Auriculoterapla): sera $i$ utllizado o protocolo Shen Men que tem efelto tranquilizante, analge $i$ slco e antialerglco; Tronco Cerebral com funci $a_{i} 0$ de sedaçáo. Grupo de Aurlculoterapla Sham: abordagem de ponto proximo $a_{i}$ a $i r e a$ da Bochecha, Indlcado para tratar paresla faclal e neuraigla do trige imeo; e outro nas Imediaçbes do ponto correspondente ao Ouvido Externo, no trago, Indlcado para tratamento de infamacioies na parte extema da oreha, zumbido e de ificit de audlc $i_{i}{ }_{i}$. Sera $i$ tolerado, no maiximo, perda de 3 sesso ies por sujetto, desde que najo sejam consecuntias, pois a acupuntura pode apresentar bons resultados com no mi inimo 1 sessa; $i$ por semana.

\section{Objettvo da Perqulsa:}

- Comparar a eflca icla terape iutica da auriculoterapla verdadelra e sham no tratamento de estresse Identificado nos enfermelros do Hospital Beneficeincla Portuguesa de Sajo Paulo;

- Identificar os nilivels de estresse dos enfermelros em diferentes cargos (administrativo ou assistencial) e en diferentes setores hospltalares;

- Analsar a aplcablidade dos pontos Shen Men e Tronco Cerebral para diminulcicajo de estresse, e ponto Cuvido Externo e reglajo da Face como pontos sham.

Enderoge: Av. Dr Endes do Cervelo Agule, 410

Bairro: Carquarn Cesse

UF: SPP Munielola: SAD PAULO

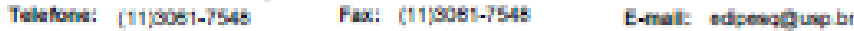




\section{ESCOLA DE ENFERMAGEM DA}

UNIVERSIDADE DE SÄO PAULO - EEUSP

Avallaciaio dos Fuscos e Benefic clos:

Segundo a proponente o estudo apresenta risco mi inimo, pols envolve questionamentos cotidlanos elementares que, em momento algum causara ${ }^{\circ}$ desconforto ao participante.

Aponta como beneficio a reduc $i a_{i}$ o dos $\mathrm{nl} i$ vels de estresse dos enfermelros do Hospital Campo de Estudo.

Avallaçå dos Rlscos $\theta$ Beneficlos:

Considerourse que 05 riscos serăo minimos, uma vez que a aplicaçăo da auriculoterapla sera felta por acupunturista.

Esta garantida a voluntariedade da participaçăo.

Considerourse que os beneficios săo significativos para 06 sujeitos da pesquisa, pela possiblidade de reduçăo dos ni ¿ivels de estresse dos enfermelros participantes do estudo.

Comentarios e Consideraçoes sobre a Pesqulsa:

Justifica-se que a auriculoterapla $e_{i}$ uma pra $i$ tica que apresenta importantes vantagens por sua simplicidade na aplcaç5o; exige pouco equipamento; najo necessita de grande espacio ni sico para sua reallzacia $a_{i}$ o e trata- se de uma te $i$ cnlca raiplda (tempo de aplicaci $a_{i}$ o de 10 a 15 minutos)e de custo mi inimo. Portanto, pode ser vantajosa, se comprovada sua efcaicla como estrategla de ententamento do estresse ocupacional em enfemeiros hosplitalares.

Considersç0es sobre 08 Termos de apresentaça obrigatorla:

Foram apresentados 05 temos adequadamente, bem como 0 orc $i$ amento inancelro detalhado.

0 cronograma de execuc $i a_{i} e_{i}$ vlaivel.

- TCLE esta $i$ claro e bem elaborado, contudo najo $e_{i}$ apresentado ao sujeito de pesquisa na forma de convite.

\section{Recomendaçoes:}

Năo ha.

Conclus $6 e s$ ou Pendenclas $\theta$ Llata de inadequaçese:

CBS: Este projeto fol aprovado por este CEP em 5/2/2013. O processo retomou para reglstro do comunicado da institulçăo co-participante, Informando a dispensa de avallaçăo do projeto pelo CEP da referida institulçăo.

\section{Situaçao do Parecer:}

Aprovado

Neceesita Apreclaç3o da CONEP:

N5๊o

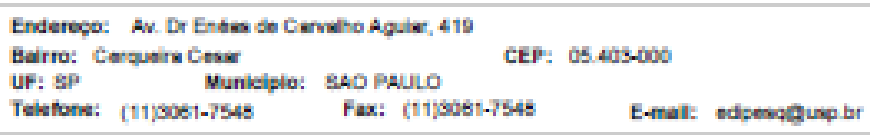




\section{ESCOLA DE ENFERMAGEM DA UNIVERSIDADE DE SÃO PAULO - EEUSP}

Consideragoses Finals a criterio do CEP:

Este parecer năo substutul a aprovaçăo da institulçăo co-participante previamente ao Iniclo da coleta de dados.

Rehterase a necessidade de reglstro dos resultados parciais e tinals na Plataforma Brasll.

SAO PAULOO, 23 de Abrl de 2013

Asainador por:

Cella Marla SIvalli Campos

(Coordenador)

Enderege: Av. Dr Entes de Cervelho Agule, 410

Bairro: Carquare Cesse

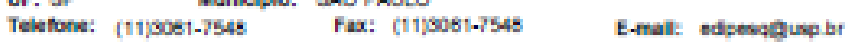




\title{
ANEXO 2
}

\section{REAL E BENEMÉRITA ASSOCIAÇÃO PORTUGUESA DE BENEFICÊNCIA - SP}

\section{PARECER CONSUBSTANCIADO DO CEP}

\author{
Elaborado pela Institulçaso Coparticipante
}

\section{DADOS DO PROJETO DE PESQUISA}

Titulo da Pesqulsa: Aplicaçăo da auricuioterapla verdadelra e sham no tratamento de estresse em enfermelros

Pesquisador: Julana Mlyuk do Prado

Área Tematica:

Versao: 3

CAAE: 12449413.9 .0000 .5392

Instutulçäo Proponente: Escola de Enfermagem da Universidade de Sáo Paulo - EEUSP

Patrocinador Principal: Financiamento Proprio

\section{DADOS DO PARECER}

Nümero do Parecer: 408.748

Data da Relatorla: 25/09/2013

Apresentaçaso do Projeto:

Projeto bem elaborado que, no momento, apresenta resposta as pendenclas da primelra apresentaçăo.

Objetho da Pesqulsa:

Comparar a eflcacla terapeutica da auricuioterapla verdadela e sham no tratamento de estresse identificado nos enfermeiros do Hospltal Beneflcencla Portuguesa de sta Paulo.

Avallaç3o dos Rlscos $\theta$ Beneficlos:

N5̆o vejo riscos na realzaçăo deste projeto.

Comentarios $\theta$ Consideraçoes sobre a Pesqulsa:

Projeto bem elaborado.

Considersç0es sobre 08 Termos de apresentaça obrigatorla:

Apresenta, neste momento, autorizaçăo da Gerencla de Enfermagem e da Medicina do Trabalho da Institulçăo campo de pesquisa.

Recomendaçoes:

Conclus 68 ou Pendenclas $\oplus$ Llsta de Inadequaçoes:

Projeto aprovado.

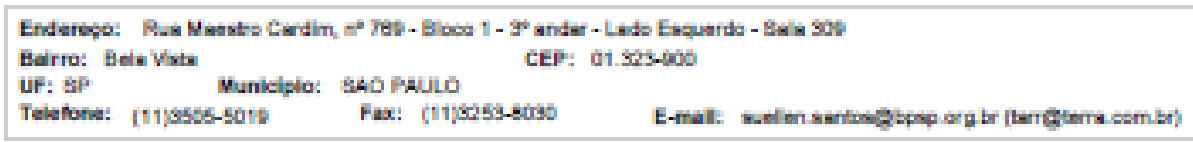




\section{REAL E BENEMÉRITA ASSOCIAÇÃO PORTUGUESA \\ DE BENEFICÊNCIA - SP}

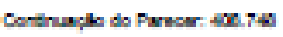

Sltuaça do Parecer:

Aprovado

Necesesta Apreclaç3o da CONEP:

N5̆

Considersç0es Finals a criterio do CEP:

Dlante do exposto, o comite de Etica em Pesqulsa da Beneficencla Portuguesa, de acordo com as

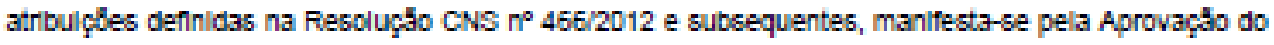
Projeto, conforme proposto para inicio da Pesquisa.

Sollcitamos que sejam apresentados a este CEP, relatorios semestrals sobre 0 andamento da pesqulsa, bem como informaçbes relativas as mocincaçbes do protocolo, cancelamento, encerramento e destino dos conhedmentos ootidos.

SAO PAULO, 27 de Setembro de 2013

Asainador por:
JOSÉ TARCISIO MEDEIROS DE VASCONCELOS
(Coordenador)

(Coordenador) 


\section{ANEXO 3}

\section{Lista de Sintomas de Stress - LSS}

Por favor, indique com qual frequência você apresenta os sintomas descritos a seguir. Assinale o número correspondente a sua resposta, obedecendo ao seguinte critério:

\begin{tabular}{|l|l|}
\hline NUNCA & $\mathbf{0}$ \\
\hline POUCAS VEZES & $\mathbf{1}$ \\
\hline FREQUENTEMENTE & $\mathbf{2}$ \\
\hline SEMPRE & $\mathbf{3}$ \\
\hline
\end{tabular}

\begin{tabular}{|c|l|c|c|c|c|}
\hline NNo & \multicolumn{1}{|c|}{ SINTOMA } & \multicolumn{4}{c|}{ CONCORDO } \\
\hline 1. & Sinto a respiração ofegante. & $\mathbf{0}$ & $\mathbf{1}$ & $\mathbf{2}$ & $\mathbf{3}$ \\
\hline 2. & Qualquer coisa me apavora. & $\mathbf{0}$ & $\mathbf{1}$ & $\mathbf{2}$ & $\mathbf{3}$ \\
\hline 3. & Tenho taquicardia. & $\mathbf{0}$ & $\mathbf{1}$ & $\mathbf{2}$ & $\mathbf{3}$ \\
\hline 4. & Tenho a sensação que vou desmaiar. & $\mathbf{0}$ & $\mathbf{1}$ & $\mathbf{2}$ & $\mathbf{3}$ \\
\hline 5. & $\begin{array}{l}\text { No final de um dia de trabalho, sinto- } \\
\text { me desgastado. }\end{array}$ & $\mathbf{0}$ & $\mathbf{1}$ & $\mathbf{2}$ & $\mathbf{3}$ \\
\hline 6. & Sinto falta de apetite. & $\mathbf{0}$ & $\mathbf{1}$ & $\mathbf{2}$ & $\mathbf{3}$ \\
\hline 7. & $\begin{array}{l}\text { Como demais. } \\
\text { 8. }\end{array}$ Rôo as unhas. & $\mathbf{0}$ & $\mathbf{1}$ & $\mathbf{2}$ & $\mathbf{3}$ \\
\hline 9. & $\begin{array}{l}\text { Tenho pensamentos que provocam } \\
\text { ansiedade. }\end{array}$ & $\mathbf{0}$ & $\mathbf{1}$ & $\mathbf{2}$ & $\mathbf{3}$ \\
\hline 10. & Sinto-me alienado. & $\mathbf{1}$ & $\mathbf{2}$ & $\mathbf{3}$ \\
\hline 11. & Ranjo os dentes. & $\mathbf{0}$ & $\mathbf{1}$ & $\mathbf{2}$ & $\mathbf{3}$ \\
\hline 12. & Aperto as mandíbulas. & $\mathbf{0}$ & $\mathbf{1}$ & $\mathbf{2}$ & $\mathbf{3}$ \\
\hline 13. & $\begin{array}{l}\text { Quando me levanto de manhã já } \\
\text { estou cansado. }\end{array}$ & $\mathbf{0}$ & $\mathbf{1}$ & $\mathbf{2}$ & $\mathbf{3}$ \\
\hline 14. & Tenho medo. & $\mathbf{1}$ & $\mathbf{2}$ & $\mathbf{3}$ \\
\hline
\end{tabular}




\begin{tabular}{|c|c|c|c|c|}
\hline 15. Tenho desânimo. & 0 & 1 & 2 & 3 \\
\hline 16. Fico esgotado (a) emocionalmente. & 0 & 1 & 2 & 3 \\
\hline 17. Sinto angústia. & 0 & 1 & 2 & 3 \\
\hline 18. Noto que minhas forças estão no fim. & 0 & 1 & 2 & 3 \\
\hline 19. Minha pressão é alta. & 0 & 1 & 2 & 3 \\
\hline 20. Apresento distúrbios gastrintestinais. & 0 & 1 & 2 & 3 \\
\hline 21. Tenho cansaço. & 0 & 1 & 2 & 3 \\
\hline 22. Costumo faltar ao meu trabalho. & 0 & 1 & 2 & 3 \\
\hline 23. Sinto dores nas costas. & 0 & 1 & 2 & 3 \\
\hline 24. Tenho insônia. & 0 & 1 & 2 & 3 \\
\hline 25. Sinto raiva. & 0 & 1 & 2 & 3 \\
\hline 26. Qualquer coisa me irrita. & 0 & 1 & 2 & 3 \\
\hline 27. Sinto náuseas. & 0 & 1 & 2 & 3 \\
\hline 28. Fico afônico (a). & 0 & 1 & 2 & 3 \\
\hline $\begin{array}{l}\text { 29. Não tenho vontade de fazer as } \\
\text { coisas. }\end{array}$ & 0 & 1 & 2 & 3 \\
\hline $\begin{array}{l}\text { 30. } \begin{array}{l}\text { Tenho dificuldades de } \\
\text { relacionamento. }\end{array}\end{array}$ & 0 & 1 & 2 & 3 \\
\hline 31. Ouço zumbido no ouvido. & 0 & 1 & 2 & 3 \\
\hline 32. Fumo demais. & 0 & 1 & 2 & 3 \\
\hline 33. Sinto sobrecarga de trabalho. & 0 & 1 & 2 & 3 \\
\hline 34. Sinto depressão. & 0 & 1 & 2 & 3 \\
\hline 35. Esqueço-me das coisas. & 0 & 1 & 2 & 3 \\
\hline 36. Sinto o corpo coberto de suor frio. & 0 & 1 & 2 & 3 \\
\hline $\begin{array}{l}\text { 37. Sinto os olhos lacrimejando e a visão } \\
\text { embaçada. }\end{array}$ & 0 & 1 & 2 & 3 \\
\hline 38. Sinto exaustão física. & 0 & 1 & 2 & 3 \\
\hline 39. Tenho sono exagerado. & 0 & 1 & 2 & 3 \\
\hline 40. Sinto insegurança. & 0 & 1 & 2 & 3 \\
\hline 41. Sinto pressão no peito & 0 & 1 & 2 & 3 \\
\hline 42. Sinto preocupações. & 0 & 1 & 2 & 3 \\
\hline 43. Sinto insatisfação com meu trabalho. & 0 & 1 & 2 & 3 \\
\hline
\end{tabular}




\begin{tabular}{|c|c|c|c|c|c|}
\hline 44. & Tenho dor de cabeça. & 0 & 1 & 2 & 3 \\
\hline 45. & Tenho as mãos e/ou os pés frios. & 0 & 1 & 2 & 3 \\
\hline 46. & Tenho a boca seca. & 0 & 1 & 2 & 3 \\
\hline 47. & $\begin{array}{l}\text { Sinto que meu desempenho no } \\
\text { trabalho está limitado. }\end{array}$ & 0 & 1 & 2 & 3 \\
\hline 48. & Tenho pesadelos. & 0 & 1 & 2 & 3 \\
\hline 49. & Tenho um nó no estômago. & 0 & 1 & 2 & 3 \\
\hline 50. & Tenho dúvidas sobre mim mesmo(a). & 0 & 1 & 2 & 3 \\
\hline 51. & Sofro de enxaqueca. & 0 & 1 & 2 & 3 \\
\hline 52. & Meu apetite oscila muito. & 0 & 1 & 2 & 3 \\
\hline 53. & $\begin{array}{l}\text { Tem dias que, de repente, tenho } \\
\text { diarréia. }\end{array}$ & 0 & 1 & 2 & 3 \\
\hline 54. & Minha vida sexual está difícil. & 0 & 1 & 2 & 3 \\
\hline 55. & Meus músculos estão sempre tensos. & 0 & 1 & 2 & 3 \\
\hline 56. & $\begin{array}{l}\text { Tenho vontade de abandonar tudo } \\
\text { que estou fazendo. }\end{array}$ & 0 & 1 & 2 & 3 \\
\hline 57. & $\begin{array}{l}\text { Tenho discutido freqüentemente com } \\
\text { meus amigos e familiares. }\end{array}$ & 0 & 1 & 2 & 3 \\
\hline 58. & Evito festas, jogos e reuniões sociais. & 0 & 1 & 2 & 3 \\
\hline 59. & Tenho vontade de ficar sozinho. & 0 & 1 & 2 & 3 \\
\hline
\end{tabular}

Caso você tenha algum(ns) outro(s) sintoma(s) que não foi (foram) mencionado(s) acima, descreva-o(s) abaixo:

\begin{tabular}{|l|l|l|l|l|l|}
\hline 60. & & $\mathbf{0}$ & $\mathbf{1}$ & $\mathbf{2}$ & $\mathbf{3}$ \\
\hline 61. & & $\mathbf{0}$ & $\mathbf{1}$ & $\mathbf{2}$ & $\mathbf{3}$ \\
\hline
\end{tabular}

